\title{
THE MAP OF TI IN KITUBA - TESTING AND EXPANDING THE TYPOLOGICAL MODEL OF THE POLYSEMY OF CONJUNCTIVE COORDINATORS
}

\author{
Alexander Andrason \\ University of Stellenbosch, South Africa
}

\begin{abstract}
The present article analyzes the polysemy of the element $t i$ in Kituba from the perspective of cognitive linguistics, by applying the framework of dynamic semantic maps and waves. The qualitative and quantitative corpus study, enhanced by evidence provided by Kituba native speakers, demonstrates the following: although $t i$ spans most parts of the typological map of the polysemy of conjunctive coordinators, its center of prototypicality is located in the initial stage (comitative) and two intermediate stages (possessive and certain types of coordinate-hood) available along the grammaticalization pathway underlying the map. This suggests a semi-advanced grammaticalization profile for $t i$. The study also proposes certain changes in the typological map of the polysemy of conjunctive coordinators, postulating new components of the map (or grammaticalization stages), and alternative linking directions. Additionally, a possible manner of introducing quantitative data (related to prototypicality) to the qualitative map of polysemy is presented. The resulting model is argued to exhibit properties typical of complexity: structural intricacy, gradience, fuzziness, and multi-causality.
\end{abstract}

Keywords: Cognitive linguistics, semantic maps, grammaticalization, conjunctive coordination, Bantu

\section{Introduction ${ }^{1}$}

The present article analyzes the polysemy and polyfunctionality of the element $t i$ (marked by a high tone) in $\mathrm{Kituba}^{2}$ (henceforth referred to as TI), which - among its various uses - is extensively employed as a conjunctive coordinator similar to 'and' in English. The study is developed within the cognitive framework of semantic maps that have a diachronic, grammaticalization-based dimension (Haspelmath 2003, Narrog \& Ito 2007, Zwarts 2010, Narrog \& Van de Auwera 2011,

\footnotetext{
${ }^{1}$ I would like to thank two anonymous reviewers and the editor for their highly valuable comments on the previous version of my paper.

${ }^{2}$ Kituba (also referred to as Kituba ya Leta, Kileta, or Kikongo) is a contact language of the Bantu family (Mufwene 1997, 2003, 2005:577). It is spoken in the Republic of Congo and the Democratic Republic of Congo (ibid.). The language derives from the usage of a Kikongo variety from Kimanyanga "as a trade language during the precolonial period" (Mufwene 2005:578, see Fehderau 1966 and Samarin 1982, 1990), although its rise and spread are also related to European colonization (Mufwene 2005). There are three main dialects of Kituba: Western, Northern and Eastern - each influenced and characterized by the local languages of the respective regions (ibid.). In this paper, the eastern variety will be studied. This variety is distinguished from the other (especially western) dialects by traits such as the presence of a progressive present form ke(le) ( $k u) d i a$ with no connective between the auxiliary and the main verb, and the use of TI as a conjunctive coordinator and comitative instead of $n a$ (compare Mufwene 2005:579). For a more comprehensive review of the history and classification of Kituba consult Fehderau (1966), Ayibite (1983), and Mufwene (1988), (1989), (2003). For a discussion of designations used to refer to the language - i.e. Kituba, Kituba ya Leta, Kileta, and Kikongo see Mufwene (2009).
} 
Georgakopoulos \& Polis 2018); and waves, which constitute such maps' quantitative modification (Andrason 2016a, 2016b). In particular, the typological map of conjunctive coordinators formulated by Haspelmath $(2004,2007)$ and subsequently expanded by Andrason (2017, forthcoming) will be tested both qualitatively and quantitatively on primarily corpus-driven Kituba data. This will lead to a further improvement of the map model of conjunctive coordinators.

The article is organized in the following manner. Section 2 will familiarize the reader with the framework underlying the research. In section 3, I will introduce qualitative and quantitative evidence related to the use of TI in Kituba, illustrating its distinct functions and senses by examples extracted from the corpus and, when necessary, from interviews. The results of this empirical study will be presented in section 4. Subsequently, in section 5, I will interpret these results within the adopted framework, additionally discussing their contribution to broader linguistic theory. Lastly, in section 6, the main conclusions will be drawn and lines of future research designed.

To my knowledge, no study has explicitly addressed the question of the polysemy of the Kituba lexeme TI - or its Bantu cognates - from a qualitative-quantitative perspective. Nevertheless, certain uses of TI (specifically, conjunctive (additive) and/or comitative) have been identified in grammatical overviews, dictionaries, word lists, and second-language teaching manuals (Swartenbroeckx 1973, Hochegger 1983, Rwanika 1986; see also Mufwene 2005).

Of course, conjunctive coordinators - and their polysemy patterns - have been extensively studied in Bantu scholarship. Most studies focus on the morphosyntactic properties of conjunctive coordinators, especially when used as true 'additive markers'. This typically involves the analysis of the word order of coordinands - see, for instance, the distinction between asymmetric and symmetric coordinating constructions (Botne 2003) - and the issue of agreement (Givón 1979, Bokamba 1985, Johannessen 1998:25, 33, Marten 2000, 2003, 2005, 2011, and De Vos \& Mitchley 2012). Scholars have also researched various prepositional functions of conjunctive coordinators in particular, their comitative, instrumental, and locative uses (Botne 2003, Fleisch 2005:97, Marten 2013, Creissles 2016) - as well as cases where they assume the role of the focus markers/adverbs 'also' or 'even' (Schneider-Zioga 2015 on Kinande, and Creissles 2016 on Tswana). Another area of research conducted on conjunctive coordinators (and commitatives) in Bantu concerns the study of their grammaticalization into reciprocal verbal extensions (Schladt 1998, Schadeberg 2003, Bostoen, Dom \& Segerer 2016), as well as their presence in expressions of possession (Du Plessis 1978:205-206, Nurse 2008:142-143 250-251, 288, Creissels et al. 2008:132, Marten 2013) and existence (Güldemann 2003, Marten 2013).

The most common conjunctive coordinator researched by Bantu linguists is $n a$ and its variants, although other types of lexemes have also been studied (e.g. le; Creissels 2016). Majority of these studies focus on properties of conjunctive coordinators in specific languages, for instance, in Chathu (Mous \& Mreta 2002), Zulu (Bosch 1985), Xhosa (Voeltz 1971, Du Plessis 1978, Sivundla 1987, Sineke 1997, Andrason forthcoming), Swahili (Marten 2000, 2013), and Tswana (Creissels 2016). Bantu conjunctive coordinators - especially the lexeme $n a$ - have also been researched from a comparative and diachronic point of view (Meeussen 1969 [1981], Nurse 2008), and within a wider cross-linguistic perspective (Heine \& Kuteva 2002). Their impact on languages from other phyla in situations of contact has also been observed (Mous 2004).

Most studies dedicated to conjunctive coordinators in Bantu have been developed within noncognitive frameworks (De Vos \& Mitchley 2012, Marten 2000, 2005, 2013). However, in various analyses, the typical grammaticalization links that underlie the semantic map of conjunctive coordinators (see Section 2) are acknowledged. Such links involve a development from comitative 
to coodirnation (Heine \& Kuteva 2002:80-83, Nurse 2008), from comitative to instrumental (Bostoen, Dom \& Segerer 2016), from comitative to possession (Heine 1997b, Heine \& Kuteva 2002, Nurse 2008:143, 250-251, 288), and from comitative to existence (Heine \& Kuteva 2002:84, Güldemann 2003).

\section{Framework ${ }^{3}$}

In this study, the issue of form-meaning pairing will be approached from the perspective of cognitive linguistics. Specifically, in order to model and explain the polysemy and polyfunctionality of TI, I will explore the idea of semantic maps (Haspelmath 2003, 2004, Narrog \& Ito 2007, Zwarts 2010, Narrog \& Van de Auwera 2011, Georgakopoulos \& Polis 2018) and waves (Andrason 2016a, 2016b). On the one hand, the qualitative profile of TI will be studied by making use of semantic maps that have a diachronic, grammaticalization-based dimension. On the other hand, the quantitative evidence related to the prototypicality of various senses and functions will be depicted dynamically by adopting the concept of a wave. In this manner, the model will give insight into the qualitative and quantitative dynamics of TI - its grammaticalization-driven range of senses and the fluctuating extent of those senses' prototypicality.

It is a widely recognized fact that virtually any language-specific component - be it a morpheme, a lexeme, or a construction - is polysemous and/or polyfunctional, and that polysemy and/or polyfunctionality constitute the norm in language(s) (Cuyckens \& Zawada 1999, Lamb 1999, Janda 2002:165). That is, a form exhibits dissimilar properties in distinct contexts. It is, thus, compatible with different semantic domains (senses) and with different grammatical roles (functions). As a result, it may relate to more than one grammatical category, including different semantic types or lexical classes (on current approaches to polysemy and polyfunctionality consult Falkum \& Vicente 2015 and Evans 2015).

This is particularly evident in the case of conjunctive coordinators. As demonstrated by various crosslinguistic studies, items that can be used to coordinate certain grammatical elements are highly polysemous and polyfunctional (Haspelmath 2004, Malchukov 2004, Mauri 2007, 2008, 2010, Narrog \& Ito 2007). They are used to express senses and functions that expand beyond the idea of conjunctive coordinate-hood, being associated with the following, additional, semantic or functional domains. First, such items can be used as adpositions expressing: a comitative sense; the idea of manner, instrument, agent or comparison; as well as certain temporal nuances (Haspelmath 2004:19, Narrog \& Ito 2007:283). Second, they can denote the idea of existence and possession. In this usage, they may be used either with BE-type verbs or alone, sometimes yielding predicative constructions that may further develop into genuine verbs (Haspelmath 2004, Narrog \& Ito 2007, Andrason 2016c, 2017, forthcoming). As parts of verbal complexes, they may contribute to tenses and aspects, such as progressives, habituals, and their more advanced grammaticalization stages - imperfectives (Bybee, Perkins \& Pagliuca 1994). They can also be employed as focal adverbs conveying senses similar to 'also, too' and 'even' (Haspelmath 2004). Moreover, they may act as contrastiveadversative particles (i.e. as adverbs or conjunctions similar to 'but'; Malchukov 2004, Mauri 2007, 2010) and discourse particles (Andrason 2016c, 2017). Lastly, they can be used as complementizers, e.g. 'that', or as “empty” clause-initial markers (Andrason 2016c, 2017).

\footnotetext{
${ }^{3}$ I have previously written papers on coordinators in Polish (Andrason 2016c, 2017) and Xhosa (Andrason forthcoming), in which I have employed a similar framework. Therefore, while not a literal reproduction, the present section partially overlaps with the introductory sections of those articles.
} 
This range of polysemy and polyfunctionality of grammatical items, that in one of their functions can be used as conjunctive coordinators, is not fortuitous. On the contrary, it is cognitively - both conceptually and historically - motivated. It reflects and emerges from the diachrony of coordinating forms and their expansion to new contexts. During these diachronic processes, every sense and every function is conceptually and historically derived from another function or use (Haspelmath 2004) through common cognitive mechanisms such as metaphor, metonymy, analogy, inference, abduction, etc. (on various cognitive extension mechanisms see, Heine 1997a, Croft \& Cruse 2004, Evan \& Green 2006, Geeraerts 2010, Riemer 2010, 2016, Janda 2016).

Even though language-specific developments of the polysemy and/or polyfunctionality of conjunctive coordinators vary, certain regularities can be observed given the above-mentioned cognitive foundation underlying meaning changes and meaning extensions. To put it simply, determined semantic and functional developments, in which conjunctive coordinators participate, are highly common. These more stable developments are referred to as (grammaticalization) paths. ${ }^{4}$ The efforts and research of typologists have led to the identification of several such grammaticalization paths (or rather, as will be evident below, grammaticalization networks) commonly travelled by conjunctive coordinators in the languages of the world. That is, given the typological prevalence of certain groups of functions associated with conjunctive constructions; the cognitive motivation linking each pair of meaning extensions; as well as the direct diachronic evidence showing how language-specific forms have evolved over time, Martin Haspelmath (2004) formulated a dynamic map of the polysemy and polyfunctionality of conjunctive coordinators. In the same year, Andrej Malchukov (2004) presented a map of contrastive and adversative markers, which is closely related to the former map. Subsequently, Narrog \& Ito (2007:283) designed a map of the comitative-instrumental domain, which also leads to conjunctive coordination. In light of data from Polish (Andrason 2016c, 2017) and Xhosa (Andrason forthcoming), I have further advanced the map of conjunctive coordinate-hood by distinguishing new domains or stages (i.e. senses and functions), and by introducing minor changes in the directionality of connections between the components of the map. The resulting structure of the map is presented below in Figure $1 .^{5}$

\footnotetext{
${ }^{4}$ For instance, conjunctive coordinators tend to derive either from comitative adpositions or from the adverbs 'too, as well' (Haspelmath 2004, Malchukov 2004; see also Mithun 1988). For other possible sources consult Mithun (1988), Malchukov (2004), and Paperno (2012). See also footnote 6, below.

${ }^{5}$ A different type of map (the so-called 'coding map') has been proposed by Mauri (2010), who has extensively discussed coordinating constructions in European languages and beyond (Mauri 2007, 2008).
} 


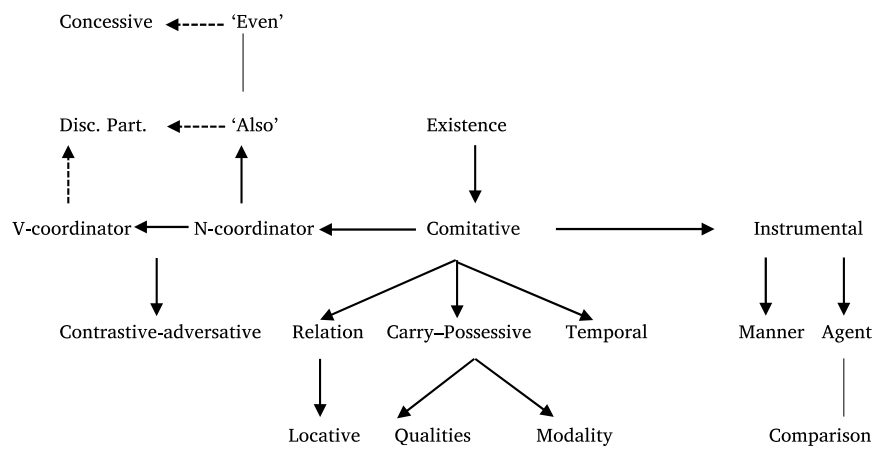

Figure 1: Map of the polysemy and polyfunctionality of conjunctive coordinators ${ }^{6}$

The map presented above is principally diachronic as it represents possible grammatical pathways of conjunctive coordinators. However, because of its cognitive foundation and crosslinguistic pervasiveness, it can also be used to depict the synchronic state of an item that, in one of its uses, acts as a conjunctive coordinator. In that manner, the synchronic map of an item refers to the grammaticalization process that underlines that form - it shows how the conceptual extensions of meaning have actually, or hypothetically, proceeded (Haspelmath 2003, Narrog \& Ito 2007, Narrog 2010, Narrog \& van der Auwera 2011, Janda 2015:137). ${ }^{7}$

This type of form-meaning representation enables us to account for the meaning of items that, due to the intricacy of their polysemy and polyfunctionality, resist an easy classification into neat, discrete, and static categories. This is possible due to the following properties offered by the model. On the one hand, it allows for a macroscopic, synthetic, and holistic perspective, depicting the total polysemy and/or polyfunctionality of a form as cognitively motivated and, thus, coherent - both conceptually and diachronically. On the other hand, it allows for a microscopic, analytic, and atomistic analysis, giving access to the entire semantic and functional variability of a form. As a

\footnotetext{
${ }^{6}$ This map has been adapted from Andrason (2017, forthcoming) following Haspelmath (2004:24) and Malchukov (2004). In the map posited by Malchukov (2004) and Andrason (under review), two separate senses are distinguished: contrastive and adversative. Additionally, Malchukov (2004) and Andrason (under review) distinguish a mirative sense, linking conjunctive coordinators to an adversative function. For the purpose of this study, these more fine-grained distinctions are irrelevant. Therefore, a coarse-grained term "contrastiveadversative' is used, and the mirative is omitted. It should also be noted that possessive constructions can yield further meaning extensions, producing TAM grams (Bybee, Perkins \& Pagliuca 1994, Andrason forthcoming). Furthermore, the map presented in Figure 1 is not exhaustive, as the idea of conjunctive coordinate-hood may originate from other sources, e.g. comparative constructions ('as, like'), quantifiers ('two', 'both', 'all'), the so-called 'coordinative pronouns', and consecutive markers (Mithun 1988, Vydrin 2010, Paperno 2012). Moreover, both sources of the map ('also'/'even' and comitative) emerge from more basic lexemes (see further below in this paper). Concerning the relationship between a concessive value and 'even' see Andrason (2017, forthcoming; compare with Malchukov 2004). The links that are tentative are marked by dashed arrows.

7 In the former case, the map can be contrasted with direct diachronic evidence demonstrating the grammaticalization path of the studied form. In the latter case, which is common in African languages due to the absence or scarcity of long-term diachronic evidence, the map is used as a template. That is, the mapping of a form is mainly derived from the array of senses and functions exhibited synchronically by that form, and its compatibility with the typologically-plotted grammaticalization map (compare Heine 1997a).
} 
result, it preserves and ensures both the global unity and internal complexity of an item (Janda 2015:137). ${ }^{8}$

Classical semantic maps are mostly qualitative. They depict the array of senses or functions as a network (or a path) of connected components. However, the components of the map representing a language-specific construction are not equally relevant. They differ with respect to prototypicality, some being prototypical, others being non-prototypical, and yet others exhibiting an intermediate, semi-prototypical status. Even though prototypicality is a complex matter, one of its important indicators is frequency. Commonly, frequent senses or functions are prototypal - they are entrenched, semanticized, and associated with the form (i.e. "first-come-to-mind"). In contrast, infrequent senses and functions are usually more pragmatic - either less entrenched (innovative), or well-entrenched but archaic - limited to rare or highly specific contexts, and generally not associated with the form (Gries \& Stefanowitsch 2006, Gries 2006, Gilquin 2006, Dąbrowska \& Divjak 2015). ${ }^{9}$ When the information related to prototypicality is introduced, the model takes a two-dimensional wave form. To be exact, the horizontal $x$ axis representing the qualitative range of senses or functions - which directly draws on a qualitative dynamic map - is accompanied by the vertical $y$ axis specifying the degree of prototypicality (see Figure 2). In this representation, the wave peak indicates the prototypicality zone of the form within its entire range of attested semantic possibilities (for a detailed presentation of the wave model consult Andrason 2016a, 2016b, Andrason \& Locatell 2016).

Other representations of frequency are also possible. The frequency of senses can be indicated by the size of the nodes; the length of the connecting lines or edges (cf. the concept of 'proximity' in van der Auwera 2013); the width or thickness of the edges (Cysouw 2007); and differences in the shapes of the edges (Narrog \& Ito 2007; for a comprehensive discussion of possible manners of visualizations, consult Georgakopoulos \& Polis 2018:12-15).

\footnotetext{
${ }^{8}$ Crucially, the coherence of a form does not lie in the idea of an invariant, abstract meaning that would be present in all of the form's uses. It resides in the cognitive process that connects all the components of the map through their family resemblance. While two adjacent senses or functions share certain properties (which in fact enables the very extension of one from the other, and ensures their direct conceptual and historical connection) distant components of the map may fail to share any property. It is rather the reiteration of cognitive mechanisms linking each pair of adjacent elements (i.e. the predecessor with its immediate successor) that guarantees the unity of the form.

${ }^{9}$ The link between frequency and prototypicality is a complex matter, being related to the issue of corpus representativity, context-specific frequency patterns, the overall frequency of a context, and the domainspecific frequency pattern. Prototypical does not mean only frequency. Other features such as productivity also play a significant role. Nevertheless, a crude (global) frequency of a semasiological type usually gives a relatively representative picture of the degree of a feature's prototypicality. For a more thorough discussion of frequency in cognitive semantics refer to Glynn (2010), Gries \& Divjak (2010), Glynn \& Fischer (2010), and Dąbrowska \& Divjak (2015). Regarding the concept of prototypicality, consult Evans (2006), Geeraerts (2010:183-189) and Riemer (2016).
} 


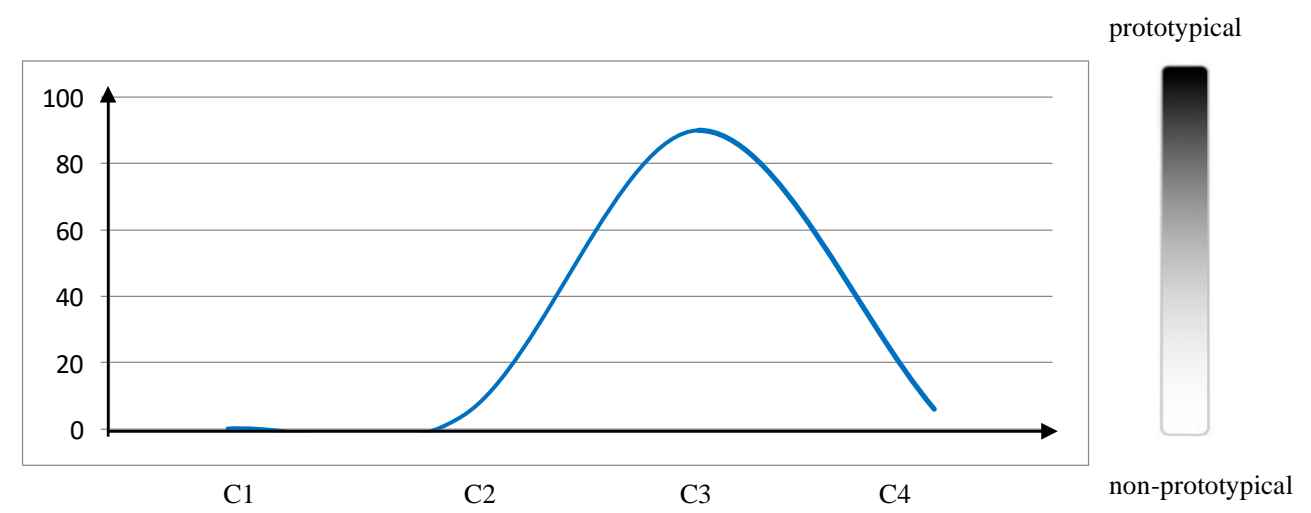

Figure 2: A qualitative-quantitative map of a language-specific construction (adapted from Andrason 2016b) $)^{10}$

As is common in cognitive linguistics and typological studies, the meaning of a form attested in a particular example (usually referred to as its sense) will be understood as the information conveyed by that form in that specific context. The sense is, thus, invariably viewed as a contextual, constructional, and emergent phenomenon. It emerges through the interaction of the form's semantic potential with a broadly understood environment - the particular situation of use, in any type of construction. As a result, other lexemes and grammatical elements constantly contribute to the meaning of the form, activating or singling out a specific sense from the wide range of available possibilities. Indeed, all components of the semantic potential - visualized as sections of a map or a wave - are equally contextual, even though some are more entrenched and/or prototypical than others. Crucially, there need not be one invariant semantic "string" present in all the senses, or one basic value from which all the other senses are derived "on-line" as contextual realizations (for details of this approach to meaning, consult Andrason \& Locatell 2016 and the references therein).

Overall, the map- or wave-structured approach to a form's semantics constitutes an alternative to a more monosemous view of meaning in terms of an invariant semantic core (the so-called basic or abstract meaning) and contextual modulations produced on-line (cf. Janda 2015, Andrason \& Locatell 2016).

\section{Evidence}

As will be manifest from the subsequent discussion, TI is highly polysemous and polyfunctional it is compatible with various semantic domains and grammatical functions. In this section, I will describe this semantic-functional variability of TI both in qualitative and quantitative terms. For this purpose, I analyzed the 494 cases of TI that appear in a Kituba translation of the Gospels of Matthew

\footnotetext{
${ }^{10}$ As waves are necessarily language-specific models, they are not typological. The wave in this figure does not refer to any concrete construction in any language - it is only designed to illustrate the adopted technique of modelling. The digits on the left (the $y$ axis) make reference to the attested frequency, which is, to an extent, correlated with the degree of prototypicality (on the right). The sections on the horizontal $x$ axis $(\mathrm{C} 1, \mathrm{C} 2, \mathrm{C} 3$, C3) make reference to different diachronic stages or semantic/functional prototypes (categories) with which the form is synchronically compatible (or not). The correlation of the arguments of the $x$ axis with the values of the $y$ axis delivers the specific wave shape that encapsulates the qualitative-quantitative profile of the form.
} 
(Mt) and Mark (Mk), which form parts of Biblia: Mbalula ya Ntsi-Ntoto ya Mpa (2015) - the New Testament in Kituba. In a few instances, the corpus study will be complemented by examples elicited from Kituba native speakers.

My primary corpus is a translated and highly stylized text. In some cases, its language bears marks of forced translations that seek to imitate French or English texts. Of course, one would wonder, how 'natural' or 'real' such a language is, and, thus, to what extent it is representative of naturalistic Kituba. It is therefore crucial to state that my informants - who also provided the other extra-biblical examples - have generally accepted the uses of TI in the biblical corpus and corroborated their grammaticality. As far as the extra-biblical examples are concerned themselves, these were elicited from two native speakers of Kituba who had resided in South Africa for one and two years, respectively. The elicitation consisted of translations from English, filling-in-gaps exercises, and/or grammaticality judgements of constructed sentences. The explanation of the tasks and the discussion of the provided examples were conducted in English and Lingala.

As mentioned in footnote 2 , the present study concerns principally the eastern Kituba variety in which TI is used instead of $n a$ in various additive, commitative, and possessive functions, and their extensions (Mufwene 2005:579). The "TI dialect" is also the variety spoken by my informants.

TI is extensively used as a conjunctive coordinator, commonly approximating the operator $\wedge$ in first degree classical propositional logic or $\cap$ in Set Theory. Overall, there are 126 cases of this semantic-functional domain in the analyzed corpus. This equals more than a fourth of all the instances of TI, to be exact $25.5 \%$.

However, not all constituents can be conjoined by TI. TI can link noun phrases, being the most common grammatical item that coordinates nouns (see examples 1.a-b below). In the analyzed corpus, this function is highly frequent, being found in 112 instances $(22.7 \%)$.

\begin{tabular}{|c|c|c|c|c|c|c|}
\hline a. & $\begin{array}{ll}\text { Yuda } & \text { butaka } \\
\text { Yuda } & \text { give.birth.PAST }\end{array}$ & & $\begin{array}{l}\text { Peresi } \\
\text { Peres }\end{array}$ & $\begin{array}{l}\mathbf{t i} \\
\mathrm{TI}\end{array}$ & $\begin{array}{l}\text { Zer } \\
\text { Zerc }\end{array}$ & $(1.3)^{11}$ \\
\hline & \multicolumn{6}{|c|}{ 'Judah became father to Perez and Zerah' } \\
\hline b. & $\begin{array}{ll}\text { Yandi } & \text { bakaka } \\
\text { he } & \text { take.PAST }\end{array}$ & $\begin{array}{l}\text { mwana } \\
\text { child }\end{array}$ & $\begin{array}{l}\mathbf{t i} \\
\mathrm{TI}\end{array}$ & $\begin{array}{l}\text { mama } \\
\text { mother }\end{array}$ & $\begin{array}{l}\text { na } \\
\text { of }\end{array}$ & $\begin{array}{l}\text { yandi (Mt 2.21) } \\
\text { him }\end{array}$ \\
\hline
\end{tabular}

Nominal coordination also includes pronouns, which can be conjoined to other pronouns (2.a) or to nouns (2.b):

$\begin{array}{lllll}\text { a. } & \text { Kaka nge ti } & \text { yandi (Mt 18.15) } \\ \text { only you } & \text { TI } & \text { him } \\ \text { 'Only you and him' } & & \\ \text { b. } & \text { Yandi ti } \quad \text { bantu } & {[\ldots] \quad \text { waka }} & \text { nzala (Mt 12.3) } \\ \text { he } \quad \text { TI } & \text { people } & \text { sense.PAST } & \text { hunger } \\ & \text { 'He and the men with him were hungry' }\end{array}$

TI may likewise connect prepositional phrases. Most commonly, such prepositional phrases are headed by the prepositions $n a$ and $y a$. There are 14 cases of this type in the analyzed corpus, which constitute $2,8 \%$. In general terms, when used in prepositional phrases linked by TI, the preposition

\footnotetext{
${ }^{11}$ All the relevant cases of TI will be marked in bold type and glossed as TI.
} 
na communicates a broadly understood locative, temporal, or relational sense similar to 'in, at' in English (3.a) or - if employed with personal pronouns - a genitive value similar to 'of' (3.b). The preposition ya is most commonly employed in a genitival sense comparable to 'of' in English. Contrary to $n a$, which heads pronouns, $y a$ introduces nouns or noun phrases (3.c).

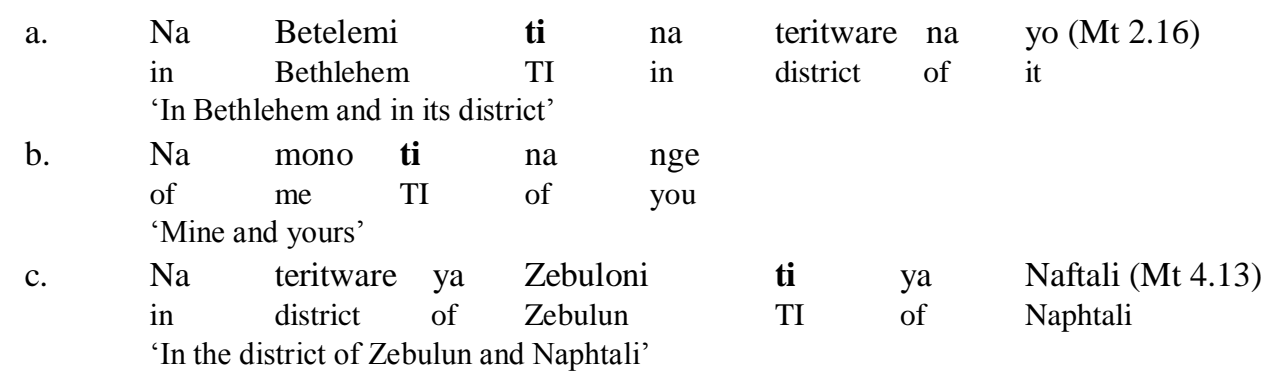

However, in cases where a prepositional phrase that is built around the preposition $t i$ 'with' (see further below in this section) is to be connected to another phrase, the linker $m p i$ is used instead of TI (see example 4 below). ${ }^{12}$ In such instances, which are unattested in the corpus, the use of two adjacent $t i$ items is avoided.

$\begin{array}{lllllll}\mathrm{Mu} & \text { ke } & \text { ntinu-ntinu } & \text { mpi } & \text { ti } & \text { kulemba } & \text { mingi } \\ \text { I } & \text { be } & \text { in.a.hurry } & \text { and } & \text { with } & \text { tiredness } & \text { much } \\ \text { 'I am in a hurry and very tired' } & & & & \end{array}$

The conjunctive coordinator TI is also avoided if the first coordinand is introduced by the preposition $t i$ 'with' (5.a) or kumosi $t i$ 'together with' (kumosi literally means 'in one') (5.b), typically used in a comitative function (see further below in this section). In such cases, mpi is again preferred. Thus, in examples (5.a-b), it is not a linear word-word adjacency like in (4) above, but rather a 'phrasal' adjacency that triggers a homophony-avoidance mechanism.

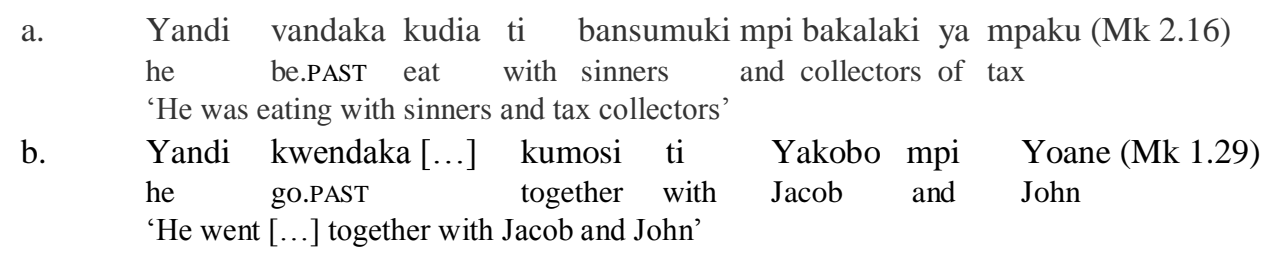

TI is extensively employed to connect items that are used in a broadly understood adjectival function. It should be noted that in Kituba most adjectival relationships are expressed through prepositional phrases (composed of the preposition/connective ya and a noun) rather than through genuine adjectives (6.a-b). This is especially true of attributive adjectives that are regularly headed by $y a$ 'of' ${ }^{13}$ Therefore, one could refer to this type of TI as a connective of modifiers, rather than an adjectival connective.

\footnotetext{
12 The prototypical meaning of $m p i$ is 'also'. One of its meaning extensions and less prototypical senses is 'and' as illustrated by this example.

${ }^{13}$ Currently, the status of $y a$ in such constructions need not be a prototypical preposition. Rather, the entire chain may have been, at least partially, grammaticalized into an attributive (modifying) adjective-like
} 
(6)

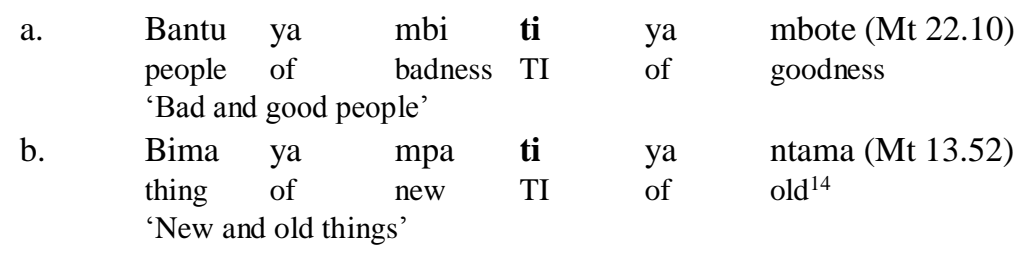

In some cases, both prepositional and adjectival interpretations (i.e. in terms of modifiers) are possible, probably attesting to an intermediate grammaticalization stage:

\begin{tabular}{|c|c|c|c|}
\hline $\begin{array}{l}\text { Bantu } \\
\text { eeople }\end{array}$ & $\begin{array}{l}\text { ya } \\
\text { of }\end{array}$ & $\begin{array}{l}\text { esti } \\
\text { East }\end{array}$ & $\begin{array}{l}\text { ti } \\
\text { TI }\end{array}$ \\
\hline
\end{tabular}

'People of (i.e. from) east and west / Eastern and western people'

Adjectival functions may, however, be expressed in Kituba without using prepositions or the connective $y a$. This sometimes occurs when the adjective appears in a predicative position. In such cases, two adjacent bare adjectives may be linked by means of TI. Although such examples are unattested in the analyzed corpus, they are fully grammatical: ${ }^{15}$

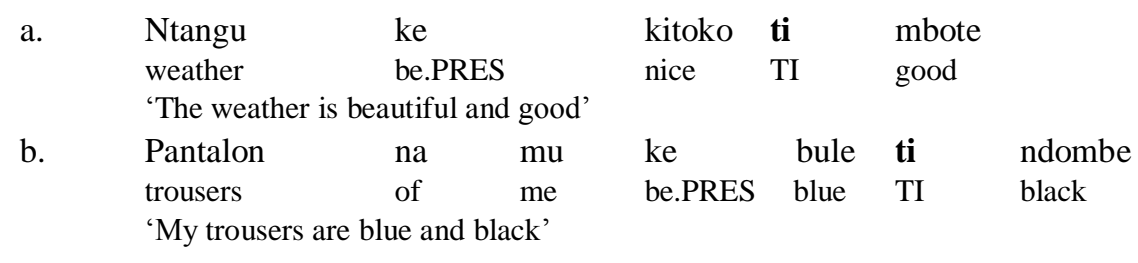

TI may also coordinate genuine adverbs as illustrated by examples (9.a-c) below. Even though possible, this usage is again unattested in the analyzed corpus, most likely given the general infrequency of adverbial coordination.

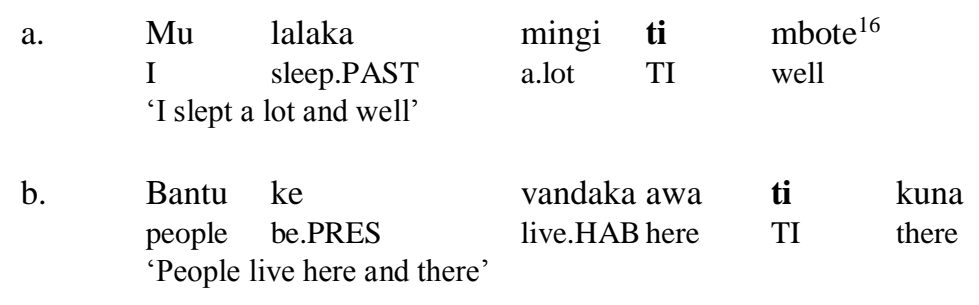

expression. It should be noted that originally, $y a$ derives from a relative agreement marker, not a preposition sensu stricto.

${ }^{14}$ The word ntama literally means 'far'. In this example a locative function has been extended to a temporal function.

${ }^{15}$ Words such as kitoko translated in constructions with $k e(l e)$ as 'nice, beautiful' can also be used nominally, e.g. kitoko na yandi (lit. 'beauty of her/his') 'her/his beauty' (see also ngolo 'strong' in yandi me zwa ngolo 'he/she has gained strength'). Their adjectival function most likely derives from such nominal uses.

${ }^{16}$ In other dialects, $m p i$ is used here. 


$\begin{array}{llll}\text { c. Bubu yai ti } & \text { mazono } \\ \text { today this } & \text { TI } & \text { yesterday } \\ \text { 'Today and yesterday' } & \end{array}$

As was the case with adjectival constructions, diverse types of adverbial relationships (e.g. time, place, and manner) are often expressed in Kituba through prepositional phrases headed, for instance, by $n a$ 'in, at, with'. In agreement with its extensive use to link propositional phrases, TI may also coordinate these types of adverbial expressions (10). Again, although fully grammatical, this usage is unattested in the analyzed corpus.

$\begin{array}{llll}\mathrm{Na} \quad \text { ntwala ti } & \text { na } & \text { nima } \\ \text { in front TI } & \text { in } & \text { back } \\ \text { 'In front and behind' } & & \end{array}$

Adverbials may also be derived from prepositional phrases that are headed by the preposition $t i$ 'with, by (means of), through'. This construction yields various expressions of manner or means (see further below in this section). Similar to the constraints exhibited by other prepositional phrases built around the element $t i$, this type of prepositional phrase cannot be linked by TI. That is, two consecutive $t i$ items are avoided and, as a result, the coordination is expressed by mpi.

While TI can link nouns, adverb(ial)s (verbal modifiers), adjectives (nominal modifiers) and (most types of) prepositional phrases, being de facto the most prototypical means of conveying the idea of nominal, adjectival, adverbial, and prepositional coordinate-hood, it cannot connect verbs, clauses, or sentences. This stands in harmony with the use of conjunctive coordinators in various Bantu languages, where distinct strategies are used to combine nominal, adjectival, and prepositional phrases, on the one hand, and finite-verb phrases (or verbal clauses) on the other hand (Du Plessis 1978, Creissels et al. 2008:140, 150, Marten 2013, Creissels 2016).

To begin with, TI cannot link verb phrases, whether finite and referring to the same subject (i.e. inflected genuine verbs), or non-finite (e.g. infinitives, stems, or bases complementing auxiliaries). ${ }^{17}$ In both cases, mpi must be used, as demonstrated by examples (11.a) and (11.b), respectively. However, TI can link infinitives if these are introduced by prepositions or prepositional phrases (11.c). ${ }^{18}$ It can also link infinitives that are used in an adjectival function (i.e. as modifiers), being headed by the preposition ya (11.d). No examples of this last type are attested to in the analyzed corpus.

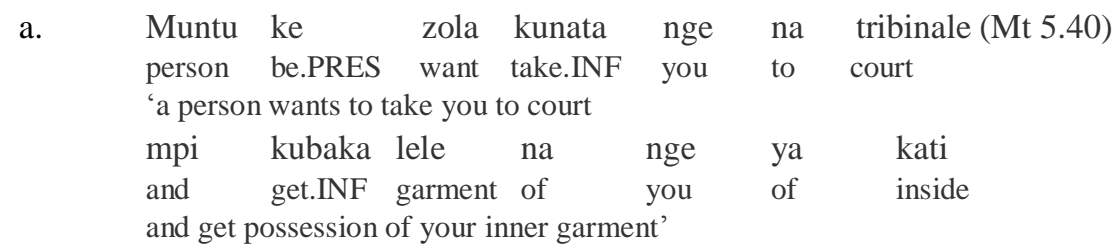

\footnotetext{
${ }^{17}$ The latter behavior contrasts with the situation found in a number of Bantu languages where conjunctive coordinators linking nouns may also connect infinitives (Du Plessis 1978, Marten 2013, Creissels 2016, Oosthuysen 2016).

${ }^{18}$ Since, in such cases, infinitives behave as vebral nouns, the presence of TI is consistent with its other uses as a nominal or prepositional linker in Kituba.
} 


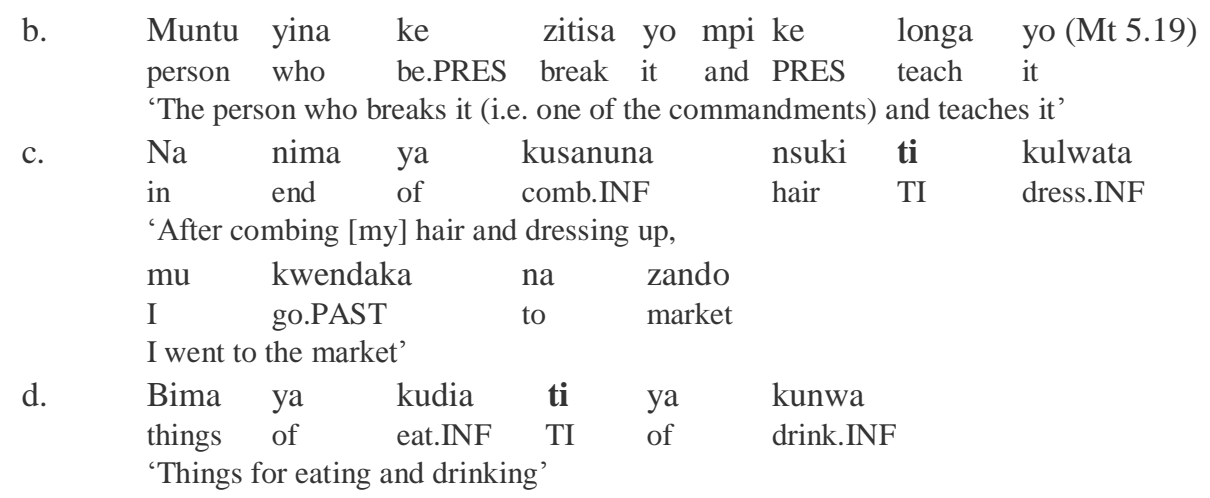

Similarly, TI cannot be employed to coordinate separate verbal clauses that contain different subjects (12.a-b). Nor can it link clauses introduced by complementizers (e.g. nde 'that') and conjunctions (e.g. sambu 'because; so that' (12.c) and kana 'if, when' (12.d)). Again, mpi is obligatory in all such cases. As mentioned previously, with some exceptions, this feature is characteristic of conjunctive coordinators across the Bantu family, as well as other African languages (Creissels et al. 2008).

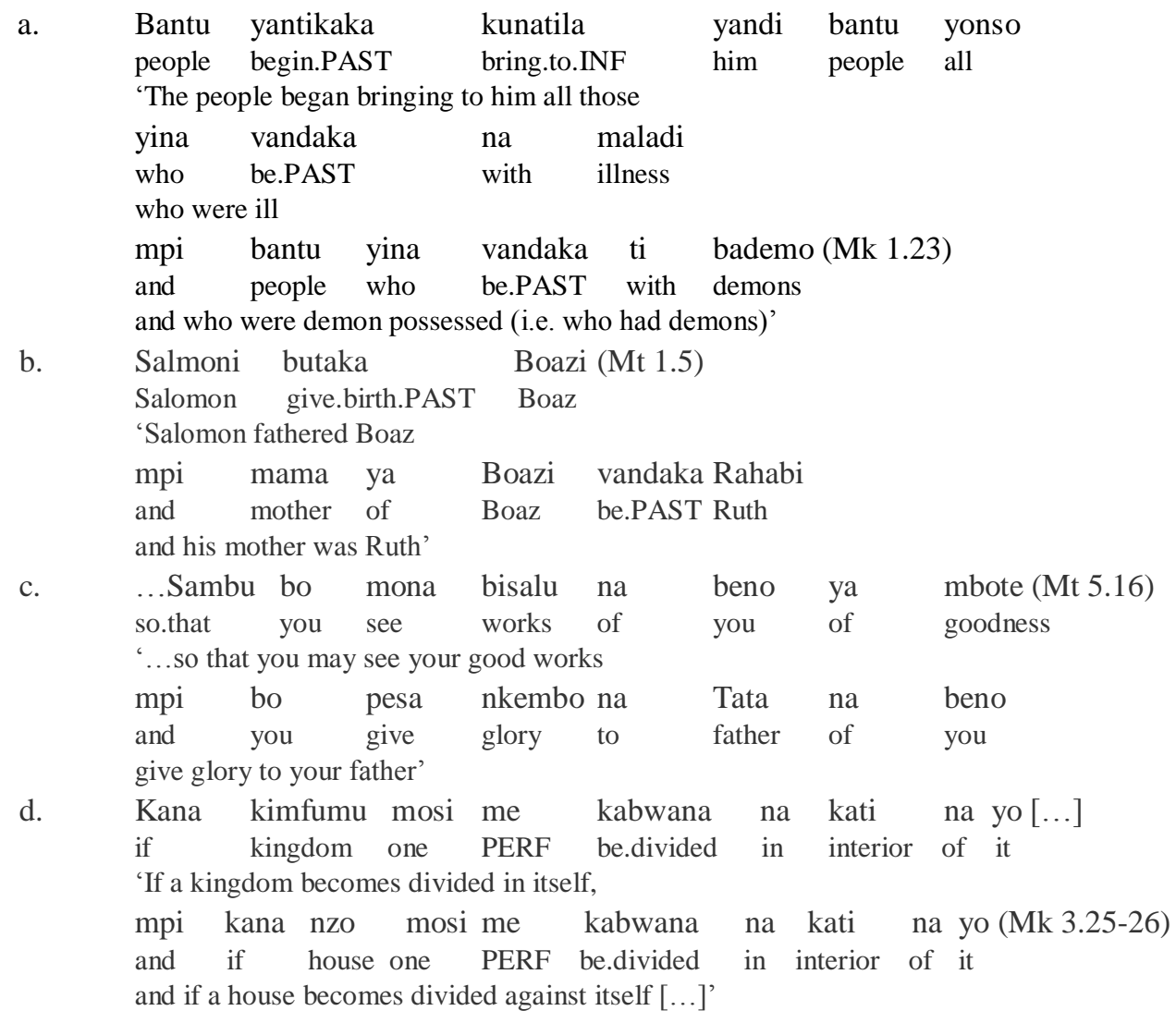


Apart from being extensively used as a conjunctive coordinator, TI commonly acts as a broadly understood comitative preposition. ${ }^{19}$ In total, there are 129 instances in which TI can be analyzed in this manner. This usage constitutes $26,1 \%$ of all the cases of TI. This type of polysemy - where a conjunctive coordinator allows for comitative uses - is widely attested in the Bantu family (cf. Du Plessis 1978, Botne 2003, Marten 2013:52, Creissels 2013:24-25). It should be noted that it is also common in non-Bantu African languages (Kilian-Hatz 1992:58) and other language phyla (Heine \& Kuteva 2002:84-85).

In its use as a genuine comitative (comitative-proper), TI expresses the idea of physical company (13.a) or spatial (and temporal) togetherness (13.b-c). There are 81 instances of this function in the corpus $(16.3 \%)$.

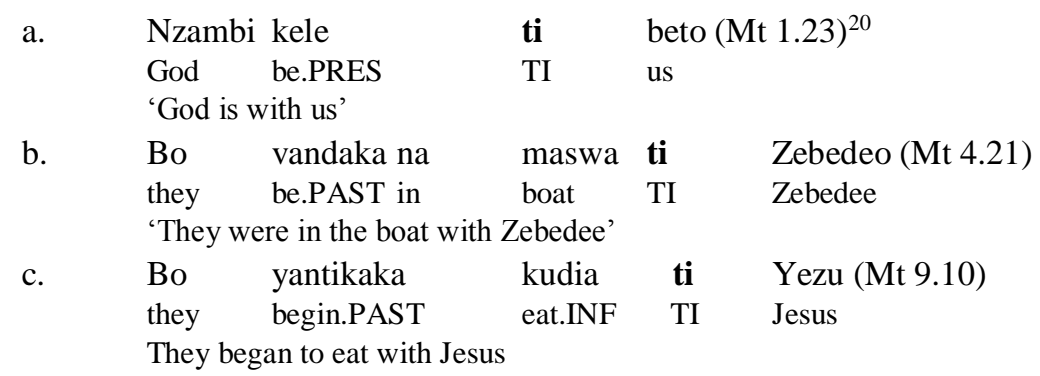

In a sentence where TI takes a comitative-proper function and is immediately preceded by an expression in which the conjunctive coordinator TI is used, the comitative TI tends to be accompanied by the adverb kumosi 'together'. This overtly marks the second lexeme TI (i.e. the one that follows the coordinator TI) for the comitative sense:

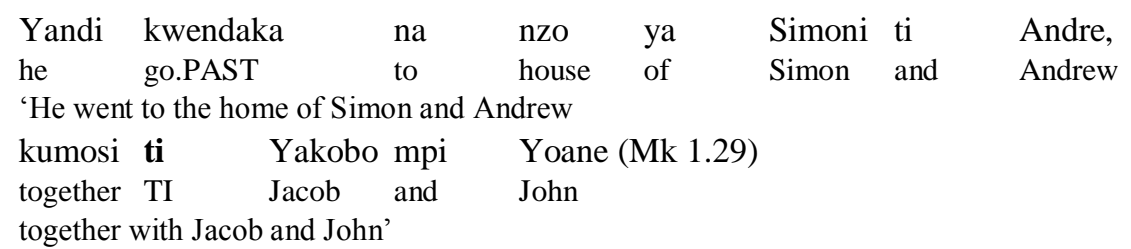

Comitative can be understood more broadly, as communicating any type of relationship that involves two or more participants, e.g. 'talk with' (15.a), 'argue with' (15.b), 'get married with (marry), and 'divorce' (15.c). This usage will be referred to as 'relational' (compare Andrason 2017, forthcoming), although it is similar to the meaning of "unspecified co-participation" (Creissels \& Voisin-Nouguier 2008:292), often associated with the conjunctive coordinator $n a$ in Bantu (Bostoen, Dom \& Segerer 2016:761-762). There are 45 instances of this use. This makes up 9.1\% of all the cases of TI.

$\begin{array}{llllll}\text { a. Bo vandaka } & \text { kusosa } & \text { kusolula } & \text { ti } & \text { yandi (Mt 12.46) } \\ \text { they be.PAST seek.INF } & \text { talk.INF } & \text { TI } & \text { him } \\ \text { 'They sought to talk to him' } & & & \end{array}$

\footnotetext{
${ }^{19}$ Alternatively, the term 'connective' could be proposed instead of 'preposition(al)' for all the cases where TI acts as a preposition. How this 'prepositional' meaning of TI is interpreted would depend on what it combines with.

${ }^{20}$ In other dialects, TI can be replaced by $n a$ in these examples.
} 


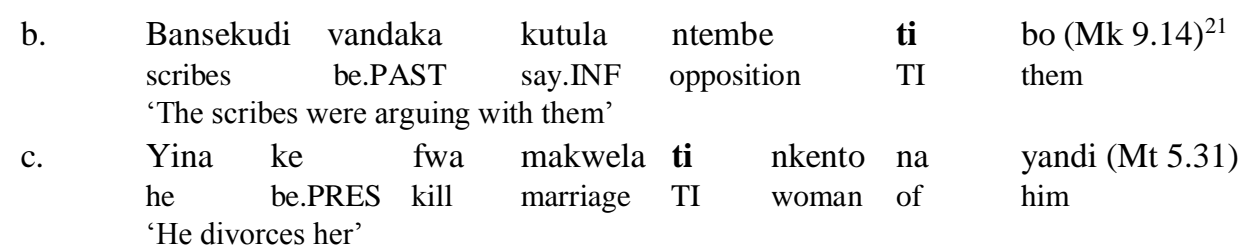

A further example of the relational value, illustrating its extension to inanimate complements, is the use of TI with the verb 'to mix' in example (16) below. Even though I am fully aware of its nonprototypicality, I include this case (and similar instances) in the relational domain of TI.

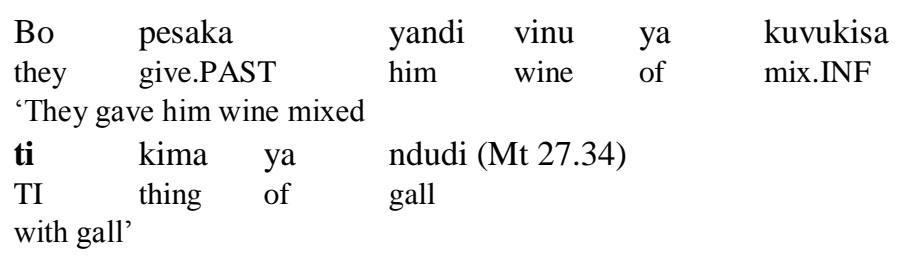

Another prepositional use of TI is the value of opposition similar to 'against'. This sense is likely derived from the comitative and/or the relational value 'with' by extending those original nuances to verbs of competing (17.a) and fighting (17.b). This usage is widely attested in the polysemy pattern of conjunctive coordinators in Bantu (e.g. in the Nguni branch; Du Plessis 1978). There are three instances of this type in the analyzed corpus, which equals $0.6 \%$.

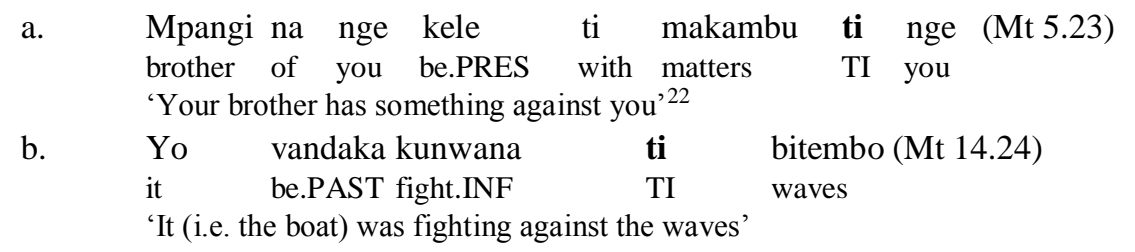

An additional domain typically associated with TI is possession. As is common crosslinguistically, this function - with all its subtypes and variations - most likely derives from a prepositional (comitative) use of TI (compare Heine \& Kuteva 2002, Andrason forthcoming). The presence of "conjunctive coordinators" in possessive constructions is widely attested across Bantu and African languages (Nurse 2008:143, 250-251, 288, Creissels et al 2008:132). Such patterns are, for instance, found in Swahili (Mkude 1996, Marten 2013:52) and Nguni languages (Oosthuysen 2016), as well as in several "simplified" contact varieties (Mufwene 2003). In total, there are 147 cases of the use of TI in the possessive domain, which constitutes $29.8 \%$.

The possessive usage appears in two main syntactic variants. In the first syntactic type, TI follows the verb vanda 'be' inflected in an appropriate tense and aspect - e.g. past (18.a) and future

\footnotetext{
${ }^{21}$ In other dialects, TI can be replaced by na in examples (15.a) and (15.b).

${ }^{22}$ It should be observed that, in this example, the first TI expresses the idea of possession (see further below in this section). Moreover, in this example, the presence of two TI items is allowed.
} 
(18.b) - or the form kele/ke found in the present tense (18.c-e). ${ }^{23}$ Such constructions constitute a regular means of expressing the idea that in many other languages is encoded by the verb 'have'. There are 125 cases of this type $(25.3 \%)$.

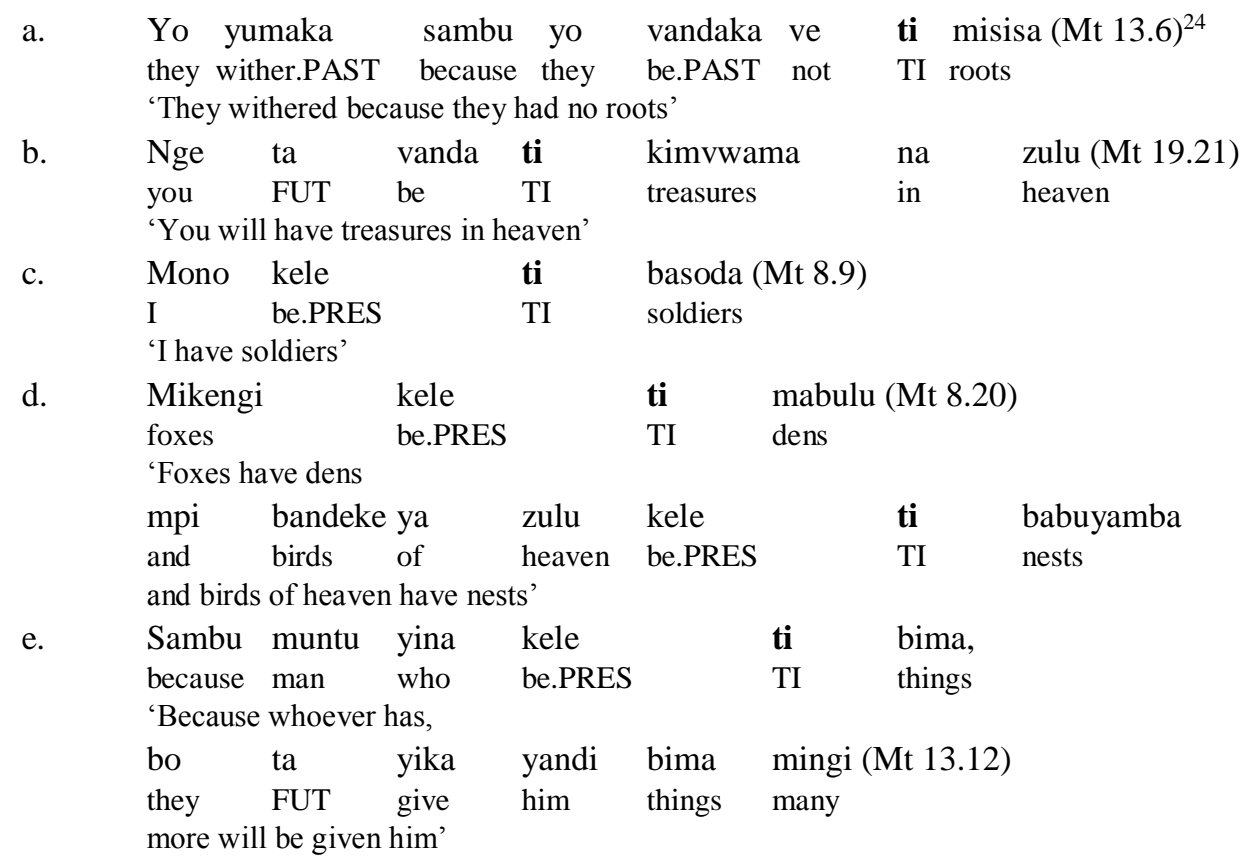

A common subtype of this class involves constructions built around nouns referring to body parts (19.a-b). Sometimes, such examples can alternatively be interpreted as presenting qualities of a person, similar to adjectives (19.c). This usage is also common in other Bantu languages, being for instance found in Xhosa and Lingala (Mini 2003:416-417, Andrason forthcoming).
a. Muntu mosi yina
vandaka ti
diboko ... (Mk 3.1)
man one who
be.PAST TI hand
b. Bika muntu yina kele ti makutu ya kuwa, kuwa (Mk 4.9) let man who be.PRES TI ears of hear.INF hear.IMP
'Let the man who has ears to listen, listen'
c. Beno yambula kuvanda ti luse ya mawa (Mt 6.16) you stop be.INF TI face of sadness
'Stop having a sad face (being sad-faced)'

In the examples analyzed thus far (18.a-e and 19.a-c), the idea of possession pertains to concrete and/or physical complements. However, possession may also be more metaphorical and/or abstract.

\footnotetext{
${ }^{23}$ The original meaning of vanda is 'sit'. Vanda is used as a suppletive of $k e(l e)$ in the past and future constructions. Overall, the possessive senses of TI do not reflect the grammaticalization of TI only, but rather the grammaticalization of the entire constructional pattern to which TI contributes, i.e. vanda ti or ke(le) ti. See, however, examples (23) and (24) in which the verbs vanda and ke(le) are absent.

${ }^{24}$ According to an anonymous reviewer, whose dialect apparently differs in certain aspects from the Kituba variety analyzed here, ve should occur at the end of this example.
} 
The latter option commonly involves expressions such as having a habit (20.a), right/authority (20.b), faith (20.c), or age (i.e. 'be $x$ years old' 20.d).

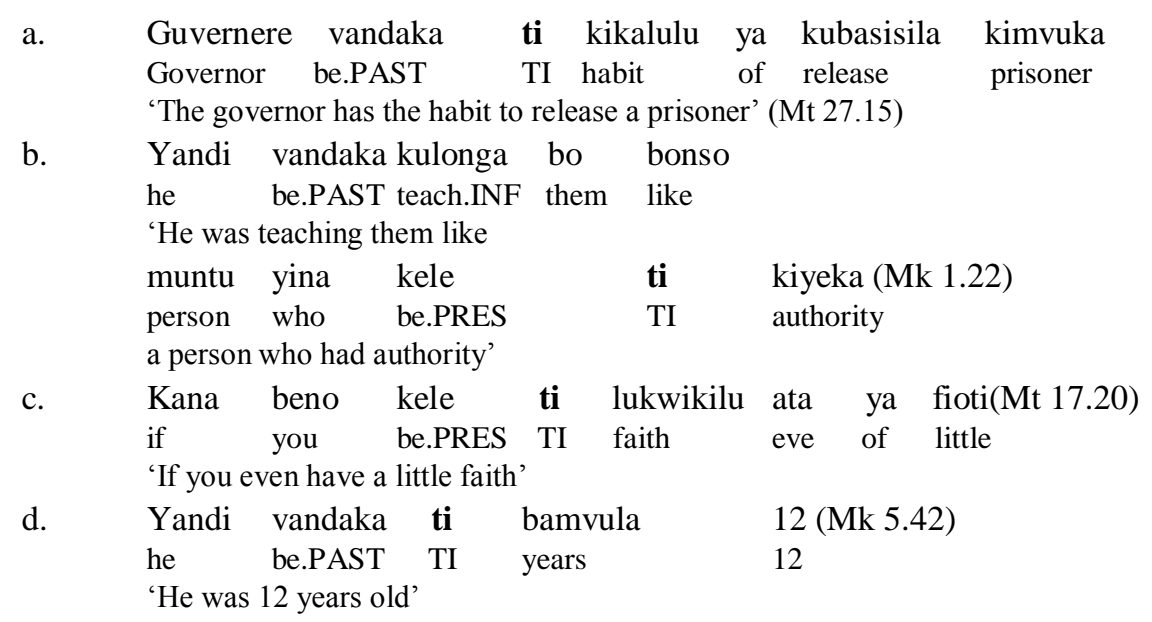

With complements that are abstract, the adjectival reading is more evident. Below, I provide two archetypal examples of this sort. However, they are not extracted from the analyzed corpus.

$\begin{array}{llll}\text { a. } & \text { Mu vandaka } & \text { ti } & \text { kulemba } \\ \text { I } & \text { be.PAST } & \text { TI } & \text { tiredness } \\ \text { 'I was tired' } & & \\ \text { b. } & \text { Mu ke } & \text { ti } & \text { kiese } \\ & \text { I } \quad \text { be } & \text { TI } & \text { joy } \\ \text { 'I am happy' } & & \end{array}$

A relatively common subtype of the possessive usage is found in locutions such as vanda $t i$ (ba)demo (22.a), vanda ti Belezebule (22.b), and vanda ti mpeve ya mbi (22.c) that express the idea of being possessed by demons. They are derived from the literal meaning 'have demon(s)', 'have Beelzebub', and 'have an evil spirit', respectively. Thus, the possession of demons, devils, or evil spirits can be reinterpreted as a quality of the subject - him or her being mentally ill because (given the biblical context) they suffer under the influence of evil. A variation of these types of expressions are constructions that indicate illnesses (22.d):

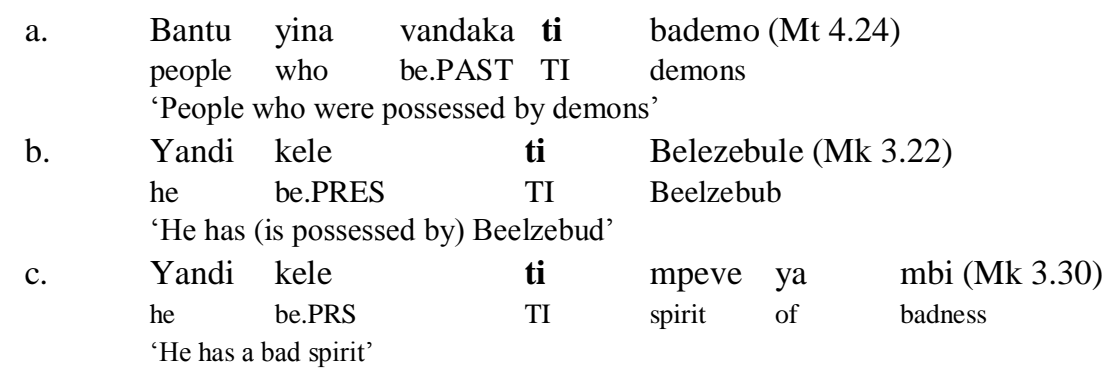


d. Bantu yonso yina vandaka ti bamaladi (Mt 4.24)

people all who be.PAST TI illness

'People who were ill (i.e. had illnesses)'

The other syntactic type of the use of TI in the possessive domain involves cases where TI follows a noun phrase, a pronoun, or a verb different from vanda/kele 'be'. In such instances, the entire construction cannot be reanalyzed predicatively as equivalent to the verb 'have'. Overall, there are 14 instances of this use $(2.8 \%){ }^{25}$

As was the case with the kele/vanda + TI sequence, this structure may involve concrete physical objects, often body parts. Frequently, these expressions can be analyzed as attributes expressing qualities, similar to adjectives:

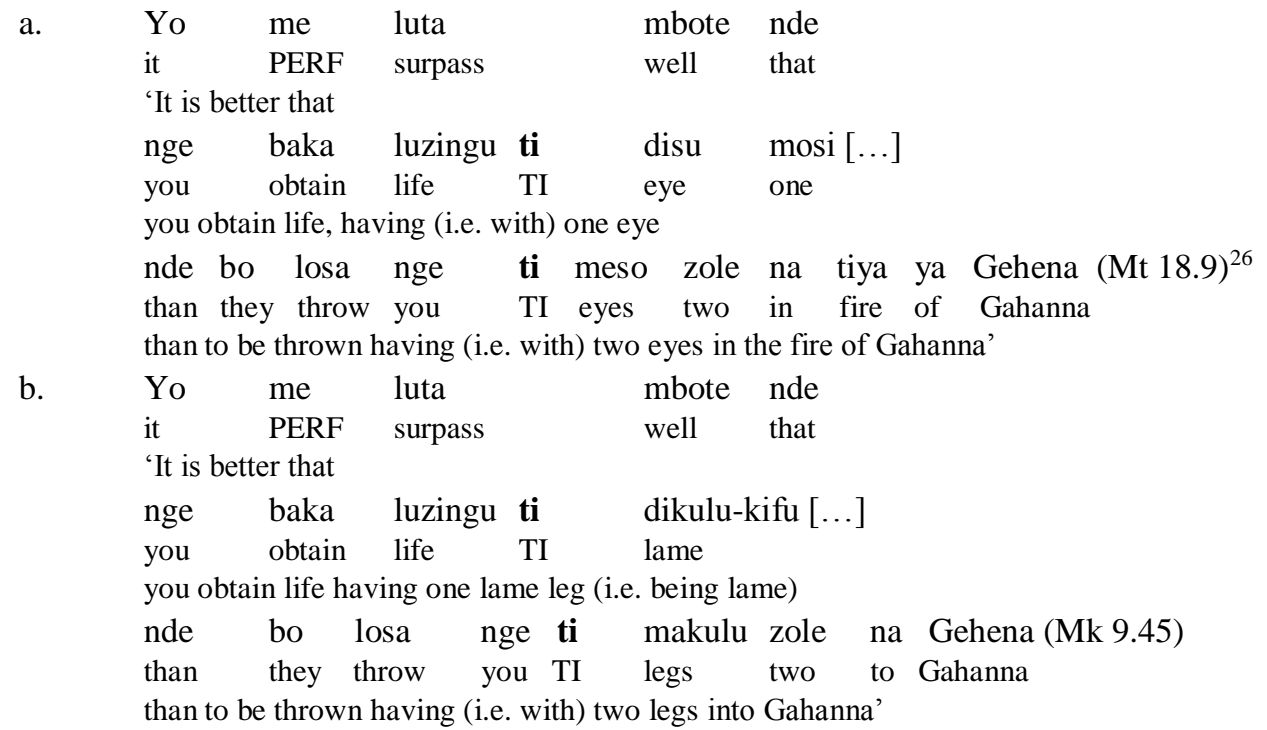

A slightly less possessive reading of such constructions - but, in contrast, their more qualitative interpretation - appears in two situations: either the complement of TI is abstract, or the possessor is inanimate and/or non-human. Example (24) below illustrates the latter option. Being aware of its lesser representativeness, I included this and similar examples in the broad possessive category. All such cases demonstrate the difficulty of fitting actual uses into discrete categorial boxes. ${ }^{27}$

\footnotetext{
25 The presence of two possessive types built around conjunctive coordinators or comitative adpositions - i.e. a type with an existential verb, and another without an existential verb - is common in Bantu languages, e.g. in Xhosa (Nurse 2008, Andraosn forthcoming). Often, the use of a sole conjunctive coordinator in the possessive function is licensed if the event concerns the present time frame. In such cases, the coordinator/commitative (e.g. $n a$ in Xhosa) behaves as a verbal base, being inflected with subject agreement markers/pronominal prefixes (Du Plessis 1978, Andrason forthcoming). In contrast, in the other time frames (past and future) and in various modal contexts (i.e. if a verb would need to be inflected in the imperative, the subjunctive, the consecutive, etc.), the presence of the existential verb (e.g. $u k u$-ba 'be' in Xhosa) is necessary. ${ }^{26}$ More idiomatically, one would say: kuluta mbote nge baka luzingu tí disu mosi. The above sentence seems to be a literal translation from French.

${ }^{27}$ Examples (23) and (24) seem to be related to the attributive (modifying) and/or comitative domains.
} 


$\begin{array}{llllll}\text { Mono } & \text { zolaka } & \begin{array}{l}\text { kubaka } \\ \text { I mbongo } \\ \text { I }\end{array} \text { want.PAST } & \text { receive } & \text { nony } & \text { mono } \\ \text { 'I would receive my money } & & & & \text { me } \\ \text { ti } & \text { mbongo ya } & \text { nkaka } & \text { na } & \text { zulu (Mt 25.27) } \\ \text { TI } & \text { money of } & \text { other on } & \text { top } & \\ \text { with interest (with / having other money on top)' } & & \end{array}$

There are three other senses that belong to the possessive domain, probably constituting extensions from a more literal possessive or even comitative idea. First, when accompanying the verb kuma 'reach, arrive, become', the idea of possession is interpreted ingressively as 'getting, acquiring'. There are 3 cases of this usage $(0.6 \%)$

$\begin{array}{lllll}\text { Yandi ta } & \text { kuma ti } & \text { bima mingi (Mt 13.12) } \\ \text { he FUT become } & \text { TI } & \text { things } & \text { many } \\ \text { 'He will get many things' } & & & \end{array}$

Second, with motion verbs, post-verbal TI phrases can convey the nuance of carrying something. That is, instead of implying permanent ownership, the construction rather denotes the act of transporting something in a particular time or place. There are 3 examples of this type in the analyzed corpus $(0.6 \%)$.

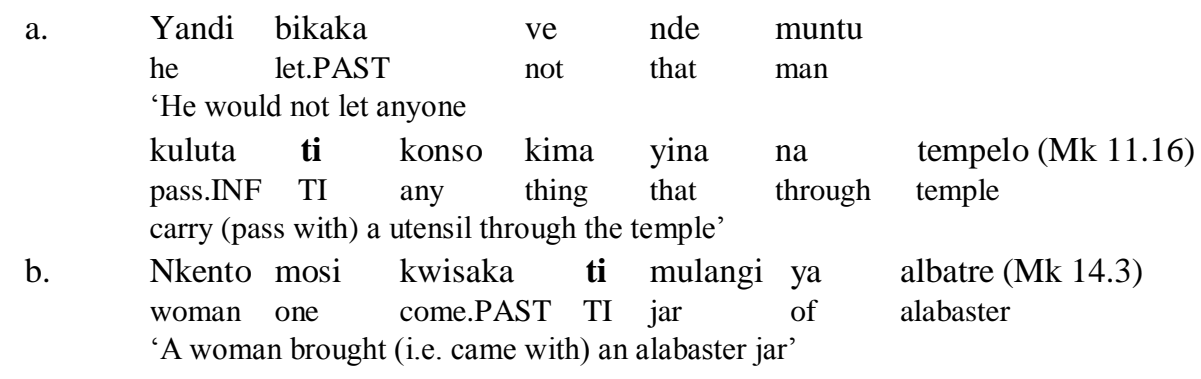

Third, TI may express the idea of containing. This reading appears if the "possessor" governing the preposition TI is an inanimate thing. Therefore, this meaning can be viewed as an extension of the possessive idea or the comitative (typical of humans and animate beings) to inanimate referents. ${ }^{28}$ Two clear examples of this type are attested in the corpus $(0.4 \%)$ :

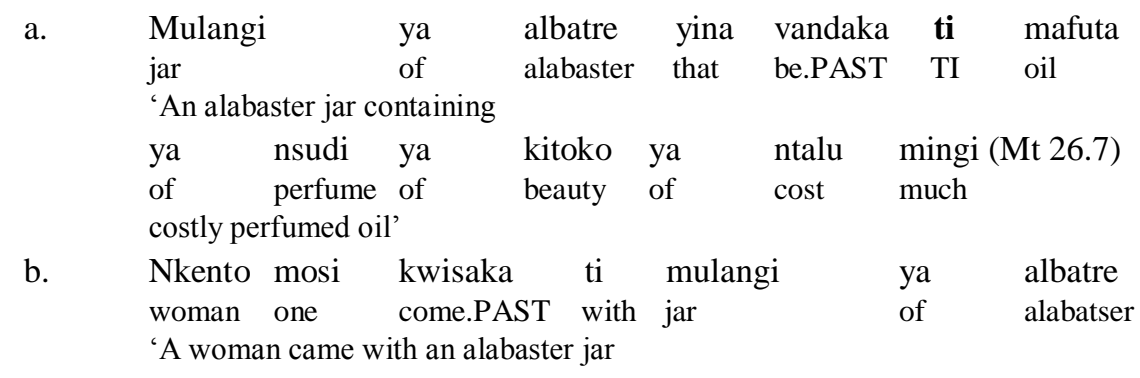

\footnotetext{
${ }^{28}$ Compare with a similar meaning exhibited by the conjunctive coordinator $n a$ in Xhosa (Mini 2003:417).
} 


$\begin{array}{lllllll}\text { yina vandaka ti } & \text { mafuta } & \text { ya } & \text { nsudi } & \text { ya } & \text { kitoko (Mk 14.3) } \\ \text { that be.PAST TI } & \text { oil } & \text { of } & \text { perfume } & \text { of } & \text { beauty } \\ \text { containing perfumed oil' } & & & & \end{array}$

The prepositional use of TI may also pertain to semantic domains other than the comitative (including the relational variant) and the possessive (which can also be interpreted qualitatively in a manner similar to adjectives). These domains are instrumental, locative, and comparison. Even though attested in the analyzed corpus and fully grammatical, the uses associated with those domains are infrequent.

First, TI can express senses that belong to a broadly understood instrumental domain. This is consistent with the semantic potential exhibited by various conjunctive coordinators in the Bantu family (Fleisch 2005:97, Bostoen, Dom \& Segerer 2016:754). In total, there are 34 cases of this type (6.9\%). They can be divided into three main classes: the expression of instrument or means; the expression of fullness; and the expression of manner.

The senses of instrument and means appear in 15 instances (3.0\%). The former value, which corresponds to an instrumental-proper usage, is found with inanimate complements, typically concrete objects:

a. Bo vandaka mpi kubula yandi na ntu ti lukengi (Mk 15.19)
they be.PAST also hit.INF him on head TI reed
'They were also hitting him on the head with a reed'
Muntu mosi ve vandaka kukuka kukanga yandi,
man one not be.PAST be.able.IN bind.INF him
'No one was able to bind him
ata ti miniololo (Mk 5.3)
even TI chains
even with chains'
Yina $[. .$.$] salaka mumbongo$
he ti do.PAST money/business
'He $[\ldots]$ did business with the talants'

In contrast, the expression of means similar to 'through, by means of', tends to appear with less toollike items such as body parts: makutu 'ears' (29.a), meso 'eyes' (29.b) or maboko 'hands' (29.c).

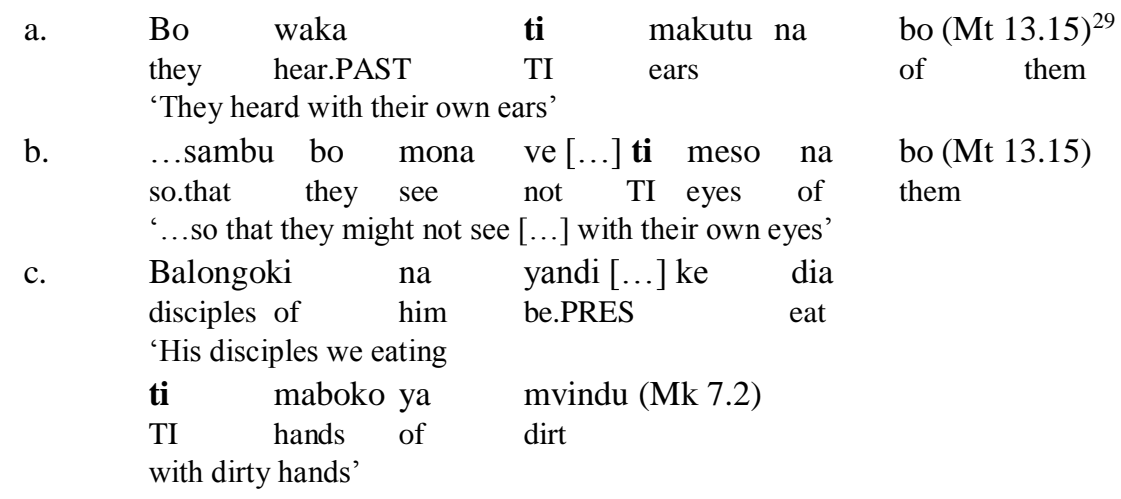

\footnotetext{
${ }^{29}$ In other dialects, $n a$ can be used here instead of TI.
} 
It is also found with complements such as e.g. ngogo 'word' (30.a), kingana 'illustration' (30.b), or mungwa 'salt' (30.c), which all fail to constitute genuine tools or instruments:

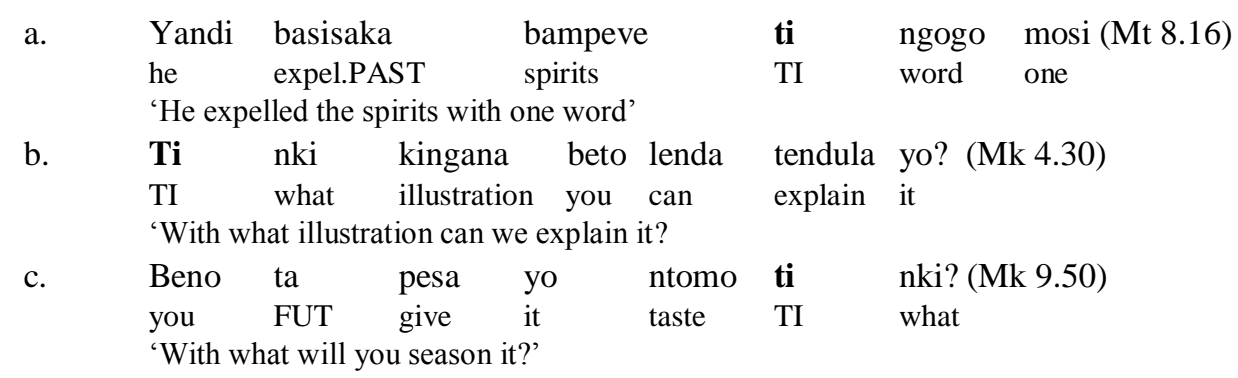

Another semantic extension of the instrumental value emerges when TI follows verbs that express the idea of 'being full', e.g. kufuluka. There are 8 cases of this usage, which constitutes $1.6 \%$.

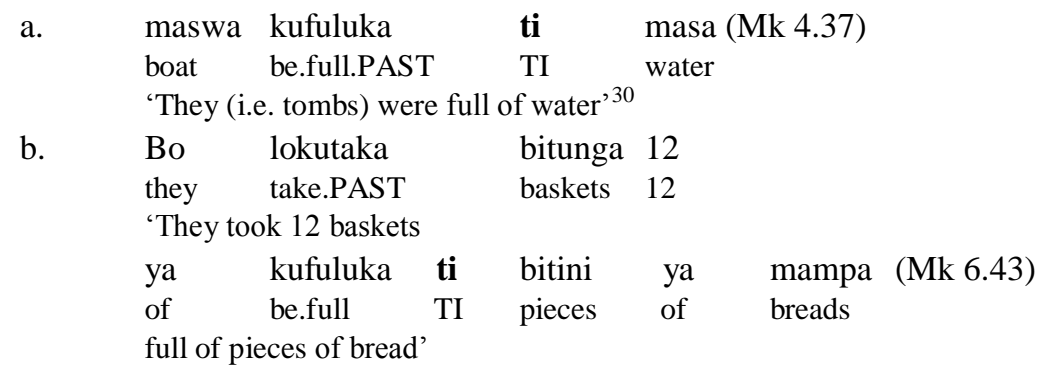

If the complement of the preposition TI is abstract (e.g. boma 'fear' or lukasi 'eagerness'), the broad instrumental value is interpreted as manner rather than an instrument or means. There are 11 cases of this type $(2.2 \%)$ :

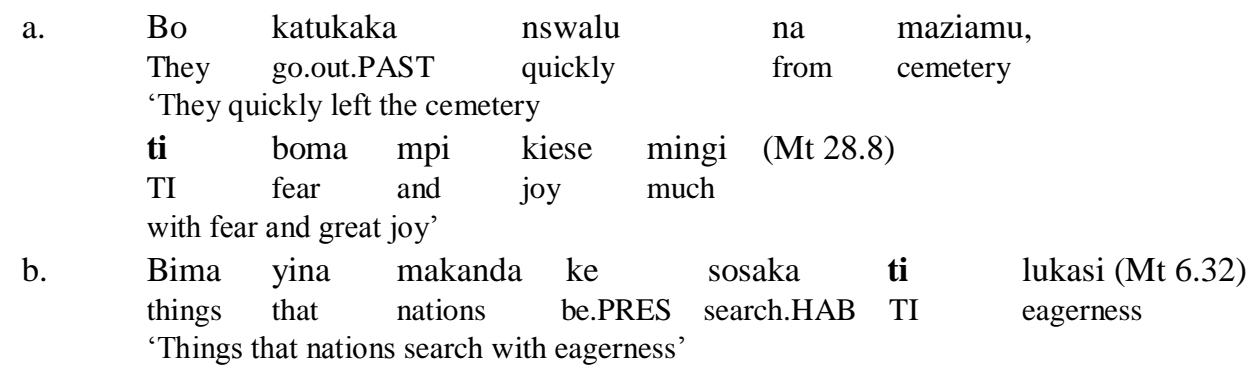

Such uses may sometimes be understood adverbially. Accordingly, they constitute similar meaning extensions to the instances in which TI-prepositional phrases (modifying nouns) were interpreted adjectivally (see examples 19.a-c, 21.a-b, 23.a-b introduced previously):

\footnotetext{
${ }^{30}$ In other dialects, $n a$ is used in this context.
} 

a. Yandi kwendaka ti mawa (Mk 10.22) he go.PAST TI grief
'He went grieving (lit. with/in grief)' 31
b. Bantu ya nkaka tubaka bo na bo ti makasi (Mk 14.4) people of some say.PAST they to them TI force 'They said to one another forcibly (lit. with force)'

Apart from the prepositional functions described so far, TI may be used with a locative sense of source, indicating distance, separation from, or being away from. This usage is regularly found if TI follows the adverb ntama 'far, long ago'. There are 19 examples of this type or $3.8 \%$. The use of conjunctive coordinators after locative expressions (e.g. locative adverbs) is not limited to Kituba, but is also attested in other Bantu languages, e.g. Swahili (Marten 2013:52) and Xhosa (kude 'far', kufuphi 'near', or kufutshane 'close' (Andrason forthcoming)).

$\begin{array}{lllllll}\text { a. Tumuna yo mpi losa yo } & \text { ntama } & \text { ti } & \text { nge (Mt 5.29) } \\ \text { tear } & \text { it and throw it } & \text { far } & \text { TI } & \text { you } \\ \text { 'Tear it out and throw it far away from you' } & & & \\ \text { b. Maswa kwendaka } & \text { mwa ntama ti } & \text { mukidi } \\ \text { boat go.PAST } & \text { quite far } & \text { TI } & \text { shore } \\ \text { 'The boat went quite far away from the shore' } & & \end{array}$

The locative type of TI may also express the idea of proximity (35.a-b). Although such cases are unattested in the analyzed corpus, they are fully grammatical:

$\begin{array}{llllll}\text { a. Kongo ke } & \begin{array}{l}\text { mfinama } \\ \text { close }\end{array} & \text { ti } & \text { France } & \text { ve } \\ \text { Congo be } & \text { TI } & \text { France } & \\ \text { 'Congo is not close to France' } & \text { ti } & \text { nzo na } & \text { mu } \\ \text { b. } \begin{array}{l}\text { Zando ke mfinama } \\ \text { market be close }\end{array} & \text { TI } & \text { house of } & \text { me } \\ \text { 'The market is close to my house' } & & & \end{array}$

Another semantic-functional domain compatible with TI is the comparative, which can involve two sub-senses: the expression of similitude and comparison. In total, there are 13 cases of this type $(2.6 \%) .^{32}$

The value of similitude regularly appears with the verb fwanana 'be like, comparable, similar' and its causative variant fwanisa 'compare' (36). There are 11 such cases in the analyzed corpus $(2.2 \%)$.

$\begin{array}{llllll}\text { Yo me } & \text { fwanana } & \text { ti } & \text { nkeni } & \text { ya } & \text { mutarde }(\text { Mk 4.31 })^{33} \\ \text { it } & \text { PERF be.like } & \text { TI } & \text { tree } & \text { of } & \text { mustard } \\ \text { 'It is like a mustard tree' } & & & & \end{array}$

The other sub-sense of this domain, the comparison sensu stricto, appears only in two instances following the noun phrase kiteso mosi. Although it is seldom found in the analyzed corpus, this

\footnotetext{
${ }^{31}$ For speakers of other dialects, $n a$ seems to be more natural than TI in this exmaple.

32 This usage is consistent with the polysemy patterns exhibited by conjunctive coordinators in Bantu languages, for example, Shona (Bostoen, Dom \& Segerer 2016:762) and Xhosa (Du Plessis 1978).

${ }^{33}$ In other dialects, $n a$ would be more natural here.
} 
construction is the most common means of encoding the first degree of comparison, namely, the idea of equality:

\begin{tabular}{|c|c|c|c|c|c|c|c|c|}
\hline a. & $\begin{array}{l}\text { Nge } \\
\text { you }\end{array}$ & $\begin{array}{l}\text { me } \\
\text { PERF }\end{array}$ & $\begin{array}{l}\text { futa } \\
\text { pay }\end{array}$ & $\begin{array}{l}\text { bo } \\
\text { them }\end{array}$ & $\begin{array}{l}\text { kiteso } \\
\text { measure }\end{array}$ & $\begin{array}{l}\text { mosi } \\
\text { one }\end{array}$ & $\begin{array}{l}\mathbf{t i} \\
\mathrm{TI}\end{array}$ & $\begin{array}{l}\text { beto (Mt 20.12) } \\
\text { us }\end{array}$ \\
\hline & \multicolumn{8}{|c|}{ 'You have paid them the same as us' } \\
\hline \multirow[t]{5}{*}{ b. } & Mono & ke & zola & kupesa & muntu & yai & ya & nsuka \\
\hline & & PRES & want & give.INF & $\operatorname{man}$ & this & of & end \\
\hline & \multicolumn{8}{|c|}{ 'I want to give to this last one } \\
\hline & \multirow{2}{*}{\multicolumn{2}{|c|}{$\begin{array}{l}\text { lufutu } \\
\text { payment }\end{array}$}} & \multicolumn{2}{|c|}{$\begin{array}{l}\text { kiteso } \\
\text { measure }\end{array}$} & $\begin{array}{l}\text { mosi } \\
\text { one }\end{array}$ & ti & \multirow{2}{*}{\multicolumn{2}{|c|}{$\begin{array}{l}\text { nge }(\mathrm{Mt} \mathrm{20.14})^{34} \\
\text { you }\end{array}$}} \\
\hline & & & is to you' & & & & & \\
\hline
\end{tabular}

Apart from the use of TI as a coordinator and preposition described so far, TI may also function as an adverb. I have already explained that certain prepositional phrases built around TI may yield the adverbial reading of manner. In contrast with those uses, this part of the article concerns the cases where TI alone behaves as a fully-fledged adverb. Such examples are overall extremely rare.

On one occasion, TI approximates the adverbs 'also, too', being found after the adversative coordinator kansi 'but'. This usage is indeed grammatical according to my informants. However, $m p i$ is the preferred form.

\begin{tabular}{|c|c|c|c|c|c|}
\hline $\begin{array}{l}\text { Beno } \\
\text { you }\end{array}$ & $\begin{array}{l}\text { vanda } \\
\text { be.IMP }\end{array}$ & \multicolumn{2}{|c|}{$\begin{array}{l}\text { mayele } \\
\text { intelligent }\end{array}$} & $\begin{array}{l}\text { bonso } \\
\text { like }\end{array}$ & $\begin{array}{l}\text { banioka } \\
\text { serpents }\end{array}$ \\
\hline \multicolumn{6}{|c|}{ 'Be cunning like serpents } \\
\hline $\begin{array}{l}\text { kansi } \\
\text { but }\end{array}$ & $\begin{array}{l}\mathbf{t i} \\
\mathrm{TI}\end{array}$ & $\begin{array}{l}\text { ntima-mpembe } \\
\text { innocent }^{35}\end{array}$ & $\begin{array}{l}\text { bonso } \\
\text { like }\end{array}$ & $\begin{array}{l}\text { bapizi } \\
\text { doves }\end{array}$ & Mt 10.10 \\
\hline
\end{tabular}

On another occasion, TI expresses the sense equivalent to the adverb 'even' or 'including', complementing one idea by another, rather than conjoining them (39). This value - usually analyzed as an additive focus particle, marker, or adverb - typifies conjunctive coordinators across the Bantu family (see Marten 2013:52 on Swahili; Schneider-Zioga 2015 on Kinande; or Creissels 2016:24 on Tswana).

Bo zabisaka $\begin{aligned} & \text { mambu } \\ & \text { matters }\end{aligned}$
they report.PAST all
'They reported everything,
ti disolo ya bantu yina vandaka ti bademo (Mt 8.33)
TI talks of people that be.PAST with demons
even (including) the accounts of the demon-possessed men'

\footnotetext{
${ }^{34}$ More idiomatically one could say: Mono ke zola futa muntu yai mpila mosi na nge.

35 The phrase ntima (ya) mpembe literally means 'heart of whiteness', i.e. 'blank heart/mind'. In this example TI could also be interpreted as the preposition 'with' used to introduce qualities. Accordingly, no uses of the focus adverbs 'too, also' would be found in the analyzed corpus.
} 
Additionally, when accompanying the verb ke(le)/vanda 'be' inflected in any tense, TI may express the idea of existence corresponding to there is in English, hay in Spanish, or il y a in French. ${ }^{36}$ This occurs in 24 instances (4.9\%). The polarity of such instances may be either positive (40.a and 40.c) or negative (40.b and 40.d). The complement of the verb may be physical, concrete (40.a, 40.b, 40.d) or more abstract (40.c). Typically, the verb is used impersonally. It appears without subject pronouns and occupies the first position in its clause (40.b-c), being only preceded by a locative adverb such as awa 'here' (40.a). Sometimes an overt subject pronoun may, however, be used (40.d).

a. Awa kele ti muntu yina me luta
here be TI man that PERF
'There is a man here that is greater than the temple'

With the verb vanda, the expletive prefix $k u$ - (identical to the infinitive form) is commonly employed:

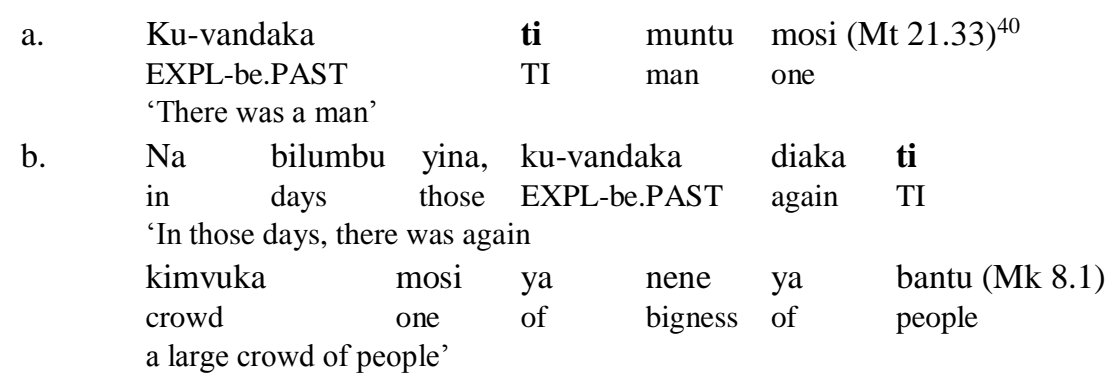

To conclude this review of the semantic and functional potential of TI, I will consider a use in which TI has lost its independence, and merged with another lexeme into an indivisible particle. It is plausible that keti, which is extensively used as a yes-no question marker similar to whether in English or $c z y$ in Polish, is a highly grammaticalized analytical construction. It originates from the

\footnotetext{
${ }^{36}$ This usage of conjunctive coordinators is found in several Bantu languages (e.g. Swahili) and other language phyla (Heine \& Kuteva 2002:84). In Swahili, kuna $(k u+$ NA) expresses existence in two construction-types: a non-tensed construction (i.e. with no verbal base) and a tensed construction (i.e. with the verb -wa 'be', e.g. kulikuwa na; Marten 2013:52-54).

${ }^{37}$ One could also say: Muntu mosi me luta tempelo or Ke na muntu mosi me luta tempelo.

${ }^{38}$ In other dialects, one could alternatively say: Ke na muntu mosi ve (ya) me luta Yoani.

${ }^{39}$ One can reformulate this sentence into: Kima mosi ata vanda ve ya beno kuka kusala ve.

${ }^{40}$ It is also possible to use the expression vandaka ná or the sole verb vandaka.
} 
existential locution $k e(l e) t i$ ? 'is there?' - an interrogative variant of the existential form ke(le) $t i$ analyzed previously in this section. Accordingly, the Kituba form would be a typological equivalent to est-ce que in French, lit. 'is it that?'. In the analyzed corpus, the particle keti appears 94 times. It should, however, be noted that given its high grammaticalization status, keti is perceived by Kituba speakers as disconnected from TI and other periphrases in which TI participates. That is, it currently constitutes an independent lexeme - an autonomous word.

Keti bantu ya $\quad \begin{array}{llll}\text { makanda } & \text { mpi } & \text { ke } & \text { salaka } \\ \text { Whether people of nations } & \text { also } & \text { be } & \text { do.HAB } \\ \text { 'Don't even the people of the nations (i.e. Gentiles) do } & & & \\ \text { ve mutindu mosi? (Mt 5.48) } & & & \\ \text { not matter one } & & \end{array}$
the same (thing)?'

\section{Results}

The qualitative-quantitative analysis carried out in section 3 indicates that TI exhibits a complex behavioral profile. On the one hand, TI is highly polyfunctional and polysemous. On the other hand, the various functions and senses with which TI is compatible differ profoundly in their frequency.

In general, TI can be used as a conjunction, a preposition, a component of a verbal complex, and as an adverb.

In a quarter of the cases, TI is used as a conjunctive coordinator, either nominal or (with a few exceptions) prepositional. TI can also link genuine adjectives, adverbs and, sporadically, infinitives, although these types of coordinating uses are unattested in the analyzed corpus. In another quarter of the examples, TI functions as a broadly understood comitative preposition. It conveys a comitative-proper sense, communicates various shades of a relational meaning, or expresses the value 'against'. The possessive uses of TI in their various semantic and syntactic subtypes are also common, appearing in nearly a third of the examples. Such possessive uses - which are most commonly found after the verb ke(le)/vanda - involve both physical/concrete and metaphorical/abstract types of possession (including illnesses and qualities) that can be reinterpreted adjectivally. With certain verbs, the possessive TI expresses ideas such as 'get', 'carry', and 'contain'. Additionally, when accompanying the afore-mentioned verb ke(le)/vanda, TI may yield an existential sense, which is attested in almost five percent of all tokens. The uses related to the instrumental domain (instrument-means, fullness, and manner) are uncommon, constituting nearly seven percent of all the instances of TI in the studied corpus. Some of these cases also allow for adverbial readings. Even less common is the use of TI to express locative ideas (separation-distance and proximity) and nuances associated with comparison (similitude and comparative). Lastly, the use of TI as an adverb ('too, also' and 'even') is extremely marginal.

The coordinating, comitative, and possessive uses are the most relevant, constituting more than $80 \%$ of all the instances of TI in total, each being similarly frequent. The remaining domains with all their subtypes - namely, instrumental, locative, comparison, adverbial, and existence - contribute much less to the behavioral profile of TI, some of them being highly marginal (e.g. 'too, also' and 'even'). The infrequency of such uses may stem from two factors: (a) the contexts in which a given sense could appear are, in general, extremely rare; or (b) a different grammatical item is more 
commonly employed to convey a certain sense (for instance, the preposition $n a$ or the adverb/conjunction $\mathrm{mpi}){ }^{41}$

The results of the semantic-functional analysis are summarized in the following table:

\footnotetext{
${ }^{41}$ Interestingly, in the Niger-Congo language Baka (ISO 639-3), there is a conjunctive coordinator that exhibits a similar phonological form (i.e. $t \varepsilon$ ) and a highly comparable semantic potential. It is used as a comitative preposition, NP-conjoining conjunction, instrumental preposition, manner preposition, and marker of verbal possession. It is also employed as a connective, a temporal conjunction, and a passive marker with impersonal agents (Kilian-Hatz 1992, Heine \& Kuteva 2002). Since Baka belongs to the Ubangi(an) branch of North VoltaCongo (Atlantic-Congo) languages, there is no direct genetic relationship with Kituba, and hence the similarity between $t \varepsilon$ and TI may be accidental. However, the affiliation of Kituba and Baka to two distinct language families does not necessarily rule out an etymological relationship between $t \varepsilon$ and TI, particularly given the only quasi-genetic origin of Kituba itself. Moreover, such Bantu-Ubungi(an) contacts did in fact exist as discussed by Donzo (2015). Therefore, borrowing is not a priori excluded as an explanation for this striking similarity.
} 

of the Polysemy of Conjunctive Coordinators

\begin{tabular}{|c|c|c|c|c|c|}
\hline \multirow[t]{2}{*}{ Domain } & \multirow[t]{2}{*}{ Function/sense } & \multirow[t]{2}{*}{ Tokens } & \multirow[t]{2}{*}{ Frequency } & \multicolumn{2}{|l|}{ Domain } \\
\hline & & & & Tokens & Frequency \\
\hline \multirow{5}{*}{$\begin{array}{l}\text { Conjunctive } \\
\text { coordinator }\end{array}$} & Nominal $^{42}$ & 112 & $22,7 \%$ & \multirow{5}{*}{126} & \multirow{5}{*}{$25,5 \%$} \\
\hline & Prepositional phrase & 14 & $2,8 \%$ & & \\
\hline & Adjectival & 0 & - & & \\
\hline & Adverbial & 0 & - & & \\
\hline & $\begin{array}{l}(\text { Prepositional })+ \\
\text { Infinitive }\end{array}$ & 0 & - & & \\
\hline \multirow{3}{*}{ Comitative } & Comitative proper & 81 & $16,3 \%$ & \multirow{3}{*}{129} & \multirow{3}{*}{$26,1 \%$} \\
\hline & Relational & 45 & $9,1 \%$ & & \\
\hline & Against & 3 & $0,6 \%$ & & \\
\hline \multirow{5}{*}{ Possessive } & $\begin{array}{l}\text { Possession } \\
\mathrm{Ke}(\text { le }) / \text { vanda }\end{array}$ & 125 & $25,3 \%$ & \multirow{5}{*}{147} & \multirow{5}{*}{$29,8 \%$} \\
\hline & $\begin{array}{l}\text { Possession (other } \\
\text { contexts) }\end{array}$ & 14 & $2,8 \%$ & & \\
\hline & Get & 3 & $0,6 \%$ & & \\
\hline & Carry & 3 & $0,6 \%$ & & \\
\hline & Contain & 2 & $0,4 \%$ & & \\
\hline \multirow{3}{*}{ Instrumental } & Instrument-means & 15 & $3,0 \%$ & \multirow{3}{*}{34} & \multirow{3}{*}{$6,9 \%$} \\
\hline & Fullness & 8 & $1,6 \%$ & & \\
\hline & Manner (Adverbials) & 11 & $2,2 \%$ & & \\
\hline \multirow[t]{2}{*}{ Locative } & Separation & 19 & $3,8 \%$ & \multirow[t]{2}{*}{19} & \multirow[t]{2}{*}{$3,8 \%$} \\
\hline & Proximity & 0 & - & & \\
\hline \multirow[t]{2}{*}{ Comparative } & Similitude & 11 & $2,2 \%$ & \multirow[t]{2}{*}{13} & \multirow[t]{2}{*}{$2,6 \%$} \\
\hline & $\begin{array}{l}\text { Comparison of the } \\
1^{\text {st }} \text { degree }\end{array}$ & 2 & $0,4 \%$ & & \\
\hline \multirow[t]{2}{*}{ Adverb } & Too, also & 1 & $0,2 \%$ & \multirow[t]{2}{*}{2} & \multirow[t]{2}{*}{$0,4 \%$} \\
\hline & Even & 1 & $0,2 \%$ & & \\
\hline Existence & & 24 & $4,9 \%$ & 24 & $4,9 \%$ \\
\hline \multicolumn{2}{|l|}{ Total } & 494 & $99,7 \%$ & 494 & $100 \%$ \\
\hline
\end{tabular}

Table 1: The qualitative-quantitative semantic and functional profile of TI

\section{Discussion}

5.1. Qualitative. In general terms, the qualitative analysis shows that the functional-semantic profile of TI is compatible with the typological map of the polysemy/polyfunctionality of conjunctive coordinators as posited in section 1 (see Figure 1). Various senses exhibited by TI especially the broad domains of coordinate-hood, comitative, instrumental, possessive, adverbial, comparative, and existence (as well as some of their subtypes) - are fully coherent with the typological map. Additionally, certain more specific subtypes of the above-mentioned domains that have been distinguished for Kituba - such as relational, 'against', fullness, or similitude - can easily

\footnotetext{
42 The terms used in the top, grey tier indicate what lexical classes TI can connect to when used as a cojunctive coordinator.
} 
be accommodated on the typological map. Nevertheless, in light of the Kituba data presented in section 3, there is indication for changes to be made to the map.

As far as the domain of coordinate-hood is concerned, TI complies with the regular cline of development from a nominal coordinator to a clausal coordinator through the stages of a prepositional, an adverbial, and a verbal coordinator (Payne 1985:5, Haspelmath 2004:12). It also attests to the gradualness of these clines. To be exact, TI is extensively used to coordinate nouns (and pronouns) and prepositional phrases. However, in the latter case, minor constraints persist - TI being sporadically replaced by mpi. TI can also coordinate adverbs and adjectives. Nevertheless, as the presence of these two lexical classes is highly limited in Kituba - both concepts being commonly expressed by prepositional phrases - the use of TI to connect genuine adjectives or adverbs is scarce. In fact, even though possible and grammatical, it is unattested in the analyzed corpus. TI may also conjoin verbs, albeit only infinitives in limited contexts. Most verbal forms cannot be connected by TI, which is the rule for clauses and sentences - a rule that complies with the use of conjunctive coordinators in Bantu (Creissels et al. 2008, Marten 2013). This means that the expansion from the node of $\mathrm{N}$-coordinator to that of $\mathrm{V}$-coordinator is gradual. Even though in Kituba this process has begun, it is far from being concluded. ${ }^{43}$

As predicted by the typological map presented in section 2, the comitative domain of TI exhibits two common variants: the comitative proper and the relational. The former is the conceptual and diachronic nucleus of the domain, while the latter constitutes its immediate extension. Additionally, in this research, a different sense has been postulated - i.e. the value 'against'. This value, which appears with verbs of fighting and competing, is regularly encoded with TI in Kituba. This is also true crosslinguistically, as, in various languages, verbs of fighting and competing may use comitative adpositions (e.g. Polish, English, and Spanish). Given this, it is plausible that the sense 'against' constitutes a further extension from the relational and comitative senses.

In Kituba, the comitative domain - particularly its comitative-proper subtype - most likely constitutes the conceptual and diachronic center of the entire map of TI. It is from the comitative usage that the other senses and functions arose, even though the semantic-functional potential of TI is currently compatible with the two possible sources of the map: comitative and focal adverbs ('too, also'). This identification of the comitative as the nucleus of the map can be hypothesized given the following facts:

a) as explained in section 2, conjunctive coordinators usually emerge from two main sources: the adverbs / focus markers 'also, too' or the comitative 'with';

b) a two-source origin of a language-specific form is highly implausible, the one-source origin being the rule. That is, it is improbable that the single form TI attested currently in Kituba would have derived from two distinct sources: one with the meaning 'also, too' and the other with a comitative value;

c) the evolution from the conjunctive coordinator 'and' (a successor of the adverb 'too', also') into the comitative 'with' is, to my knowledge, unattested. It is furthermore cognitively implausible "as the comitative is more concrete and 'spatial' than the Boolian conjunction 'and" (Andrason forthcoming). In contrast, cases of the extension from coordinators

\footnotetext{
${ }^{43}$ The domain of coordinator has, itself, most likely emerged from the comitative domain - the diachronic center of the map (see the paragraph below).
} 
(successors of the comitative source) to the adverbial domain of 'too, also' are attested (for instance in Xhosa; Andrason forthcoming). ${ }^{44}$

The possessive domain is also predicted by the map in Figure 1, most likely constituting an extension from the comitative (see also Heine \& Kuteva 2002). The possessive domain itself consists of three subtypes in Kituba. First, as in various Bantu languages (Nurse 2008), the verb ke(le)/vanda 'to be' accompanied by TI expresses the genuine possession, being, to a degree, reanalyzed as an equivalent to 'have'. Second, in ingressive contexts and/or with certain verbs of motion, the possessive is extended to the ideas of 'get-carry-bring'. Sometimes, both usages can be reanalyzed as qualitative, similar to that of adjectives (see, for instance, the expression of illnesses). This is consistent with the analysis of Xhosa where possessive $n a$-constructions (developed from a comitative use of $n a$ ) are extensively used to expresses qualities and states of ill-health. In Kituba, this process is less advanced, probably appearing in its incipient phase.

The instrumental domain - with its two subtypes: instrument-means and manner - also complies with the plotted map typologically. As is often postulated for Bantu and other languages of the world (Heine \& Kuteva 2002), in Kituba, the instrumental domain has most likely arisen from the comitative, arguably when applied to tools and concrete physical objects. Additionally in this study, a third subtype has been distinguished - the idea of 'fullness', i.e. 'being full of' or 'filled with'. It shares certain semantic features with the instrumental (i.e. instrument-means), even though it exhibits its own characteristics and status.

Another domain that fits the typological map is the comparative. As predicted by the theory, it most likely constitutes an extension from the instrumental domain. However, rather than being directly derived from the agentive value (see the map in Figure 1), with which TI is incompatible, it might have emerged from the instrumental or relational (comitative) domains. In this study, two subtypes of the comparative have been distinguished: similitude and first degree comparison. It is likely that the former sense constitutes an extension from the relational subtype of the comitative domain: i.e. 'be similar with' $>$ 'be similar to'. The latter may also have originated from the relational comitative: 'one/same size with' > 'one/same size as'. At this stage of research, the linkage relating the comparative domain of TI to the other parts of the map should be regarded as tentative.

The presence of two adverbial (focal) functions - 'also, too' and 'even, including' - is likewise compatible with the typological map, as both constitute common nodes from a crosslinguistic perspective, being also congruent with the polysemy patterns exhibited by coordinators across the Bantu family. As already explained, with respect to TI, it is likely that both functions derive from its use as a conjunctive coordinator, in this case, the nominal coordinator. This is compatible with the afore-mentioned situation in Xhosa where the coordinator $n a$ - which has similarly emerged from a comitative source - has been extended to adverbial uses of 'too, also' and 'even' (Andrason forthcoming). In Kituba, it is probable that 'also' constitutes the initial extension from which 'even' has posteriorly been derived as its focal, "emphatic" variant (compare with a similar observation concerning Xhosa; Andrason forthcoming).

The incorporation of the domain of 'existence' in the map of TI requires a more substantial change. Even though this value has been posited by Haspelmath (2004) in his original map and subsequently by myself (Andrason 2016c, 2017, and forthcoming), it seems to occupy a different

\footnotetext{
${ }^{44} \mathrm{I}$ used a similar type of argumentation in postulating the diachronic nucleus in the map of the element $n a$ in Xhosa (Andrason forthcoming).
} 
place and exhibits a different extension mechanism (see Heine \& Kuteva 2002:84). In Kituba, the existential domain has most likely emerged from the possessive domain. This is consistent with a common crosslinguistic phenomenon where possessive expressions - of which some are built around the verb 'have' - are used to express the idea of existence. For example, possessive periphrases with the verb 'have' have been grammaticalized as existential expressions in French ( $i l$ $y a$ 'there is' from the verb avoir 'have'), in Spanish (hay 'there is' from the verb haber 'have'), or in Polish (nie ma 'there is not', a negative impersonal form of the verb mieć 'have'). Kituba seems to follow this common pattern. Accordingly, in certain contexts, the equivalent of the verb 'have' the complex ke(le)/vanda + TI - is used not to express possession, but rather existence, usually of the general, indefinite character 'there is'.

Lastly, a new component must be posited in the map to accommodate the locative uses of TI in Kituba. These locative uses concern the ideas of distance (separation) and its reverse - proximity. It is plausible that both subtypes of the locative domain constitute meaning extensions that have arisen from the relational use, a sub-class of the comitative domain. It is also possible that the nuance of distance (separation) is more basic, as it can be connected to the relational or even the coordinating sense more directly. Accordingly, the expression 'to separate $x$ and/with $y$ ' would be reinterpreted as 'to separate $x$ from $y$ ', and subsequently 'be distant (be far) from $y$ '. The nuance of proximity could be developed by analogy (compare with a similar development of na in Xhosa; Andrason forthcomig; see also Marten 2013:52 on comparable uses of $n a$ in Swahili). ${ }^{45}$ At this point of the research, the position of the locative remains tentative.

Given the qualitative semantic-functional profile of TI and the most likely extension mechanisms that underlie it, the polysemy and polyfunctionality of TI can be networked by the following map (which is a slightly modified version of Map 1 introduced in section 2). ${ }^{46}$

\footnotetext{
${ }^{45}$ It should be noted that, in some languages, the preposition of separation or distance (such as from in English or, in certain contexts, TI in Kituba) can express not only motion and separation from, but also proximity to. This can be illustrated by the following uses of the preposition od in Polish: daleko od morza 'far from the sea' and blisko od morza 'close to (lit. from) the sea'. In Polish, the use of od to express proximity is most likely secondary.

${ }^{46}$ The map of TI has been postulated given the synchronic profile of this form, certain typological tendencies in the polysemy/polyfunctionality and grammaticalization of forms that, at some stage, are used as conjunctive coordinators, and the plausibility of cognitive mechanisms enabling an extension from one sense to another. A final test that could definitively corroborate the map is direct diachronic evidence - namely, the history of the form as attested in texts. Unfortunately, we do not have Kituba texts that could show how TI has been evolving over a large span of time (for instance over centuries, a time sufficient to see how the polysemy and polyfunctionality of TI have evolved). In particular, we are unable the verify if the comitative constitutes the historical nucleus of the map. Nor can we determine the lexical source of the comitative preposition from which TI has arguably derived. That is, comitative prepositions - for instance, the hypothetical source of the map of TI - are themselves highly grammaticalized reflexes of other, more concrete lexemes, or prepositional phrases built around such concrete lexemes. Was the etymological source of TI built around one of these more concrete lexemes? What type of lexeme could it have been? We know little about the history of TI and its possible lexical input. Guthrie (1970) hypothesizes that at least some cases of *-ti in Bantu might have been related to *-kati 'inside' (Guthrie 1970:3.269, 4.106). If this is true, the prepositional (and hence comitative) center of the map would be partially corroborated, although the exact relationship between 'inside' and 'with' is not clear. Overall, the relation of TI with *-kati - or with other lexemes from which it might have emerged remains speculative. Given the language-contact, "catastrophic" origin of Kituba, the diachronic evidence whose essence resides in a gradual and cognitively motivated expansion (and shrinkage) of semantic potential - may be less suitable for the corroboration of the map overall.
} 


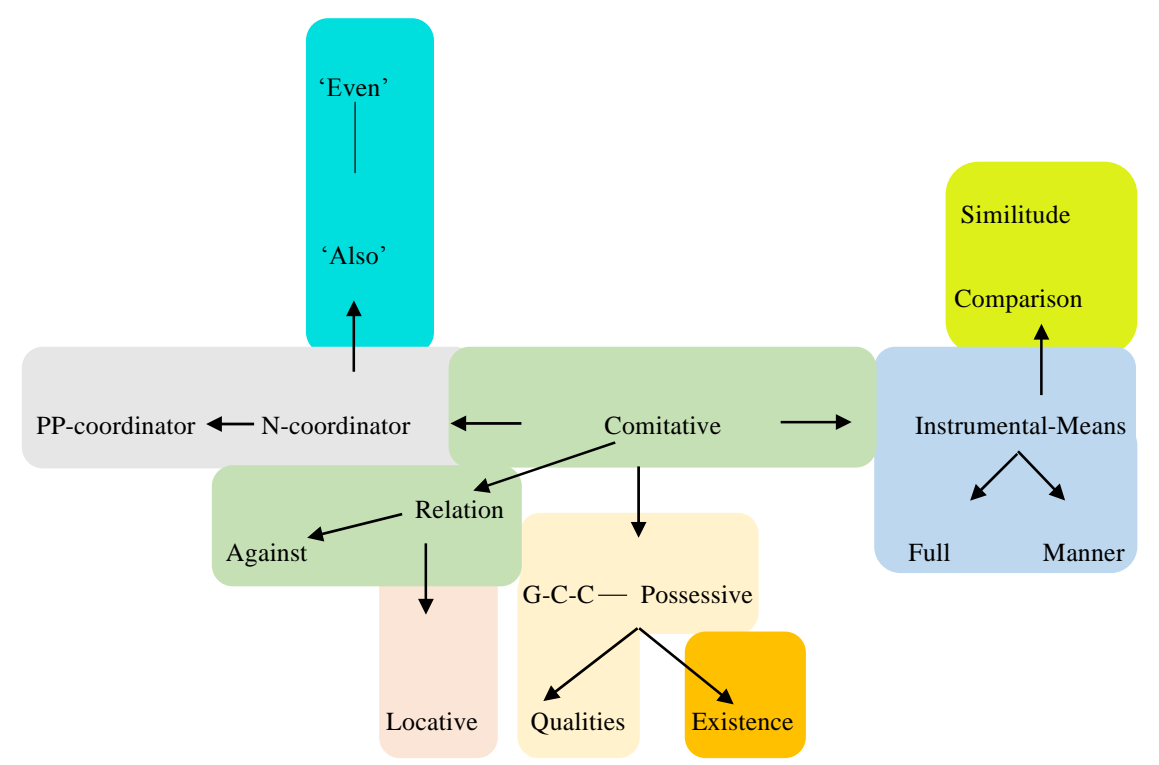

Figure 3: Qualitative map of the polyfunctionality of $\mathrm{TI}^{47}$

The evidence demonstrates that the map of the polysemy and polyfunctionality of TI - and, in general, the typological map of conjunctive coordinators - is complex and characterized by a high level of internal intricacy. First, rather than being a neat cline or a "monolithic" vector, it is a network composed of multiple branches leading to various components (senses or functions) - each branch splitting into further sub-branches. Second, senses and functions are "semantic clouds" instead of constituting separate semantic domains. We can (and probably should) represent them as clustering around certain prototypes, thus forming independent taxonomical boxes. However, what happens realistically is that each domain encompasses a variety of more or less similar uses that are related via family resemblance, each being at least slightly different from the others. The similarity or distinctiveness of such senses - and, overall, their number - mainly depends on the granularity of the map. Third - and crucially - a domain transmutes conceptually into another domain in a gradual and borderless manner, passing through an intermediate transition zone in which senses are related to more than one semantic-functional category or domain. This conceptual gradualness is, in turn, related to and reflects the process of grammaticalization underlying the map, which is also gradient. Fourth - and drawing on the previous point - the network becomes not only messy but also fuzzy. Fifth, the intricacy of the map is further incremented by the following fact: both in typological and language-specific maps, certain semantic senses and functions can be reached from different directions, i.e. by being derived from more than one domain and via more than one extension mechanism. For example, different temporal nuances can derive from the nuance of comitative and relational (e.g. simultaneity) and from the locative (e.g. the temporal nuance of separation and distance). Likewise, the idea of similitude may emerge from the relational, while a similar value of first-degree comparison can derive from the instrumental domain as proposed by Haspelmath (2004). Consequently, the qualitative model may be imagined not as bi-dimensional, but rather as

\footnotetext{
${ }^{47}$ In this map, the senses that are unattested are omitted for the sake of transparency.
} 
(multi-)folded where initially separated domains may intersect in higher dimensions (see a similar conclusion in Mauri 2010 and Andrason under review).

The discussion of the qualitative map can be concluded with the following: since the map contains a great number of senses and functions whose extent is mainly determined by granularity, each usage being somehow distinct from the others; since senses and functions are connected via an inherently gradient mechanism of family resemblance allowing for (and necessitating) fuzzy transition states; and since domains can intersect - the resulting relational network and the causal relations that underlie it are complex within the framework of complexity theory (Auyang 1998, Hooker 2011). That is to say, the model is characterized by properties such as fuzziness, gradience, a multi-causal relationship, and overall organizational intricacy (cf. Mauri 2010). ${ }^{48}$ In this manner, the map of conjunctive coordinators such as TI is compatible with the complex nature of language: it gives access to it and preserves it (on linguistic complexity consult Mufwene 2001, 2013, Miestamo, Sinnemäki \& Karlsson 2008, Sampson, Gil \& Trudgill 2009, Massip-Bonnet \& Bastardas-Boada 2013, Mufwene, Pellegrino \& Coupé 2017a, 2017b). ${ }^{49}$

5.2. Quantitative. The qualitative model designed in Figure 3 above can be accompanied by the quantitative information that relates the domains, along with their specific senses and functions, to prototypicality. One way of incorporating this information into the model is to include the digit specifying frequency in the qualitative map, in the following manner:

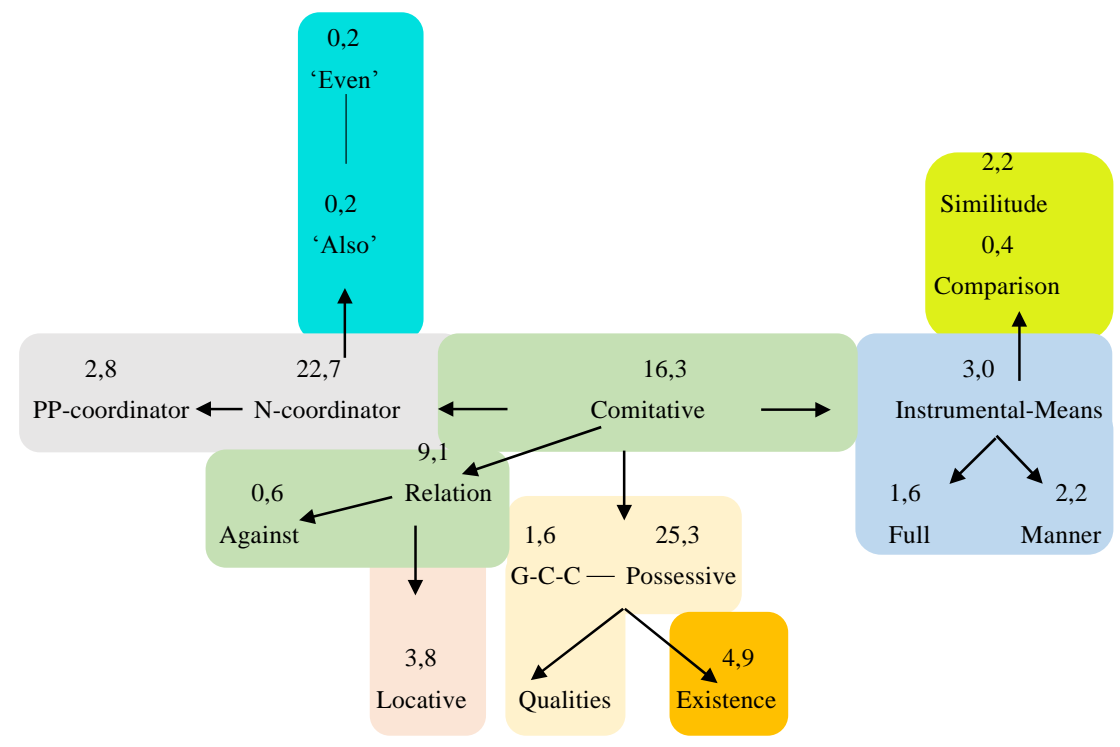

Figure 4: Qualitative map of TI with the quantitative information attached

\footnotetext{
${ }^{48}$ The more fine-grained the model is, the more complicated it becomes; that is, a larger number of extension processes take place and a larger number of intermediate fuzzy components/stages appear.

${ }^{49}$ It is likely that all grammaticalization processes are of this type - they constitute messy and fuzzy networks rather than one-dimensional, monolithic, and neat paths. Indeed, various typological maps exhibit comparable complexity. See, for instance, the map of causal, conditional, and concessive relations and the map of interclausal relations posited by Kortmann $(1997: 204,210)$, or the grammaticalization path (network) of modality designed by Bybee, Perkins \& Pagliuca (1994).
} 
Even though informative, this type of map is not intuitive. Nor does it, by its representation, have any explanatory power. One manner of improving the map's formulation is to correlate the frequency of the domains or senses (which, as explained, is related to prototypicality) with their size (cf. section 2). For the sake of simplicity, only broader domains will be represented and the size of each domain approximately correlated with its frequency.

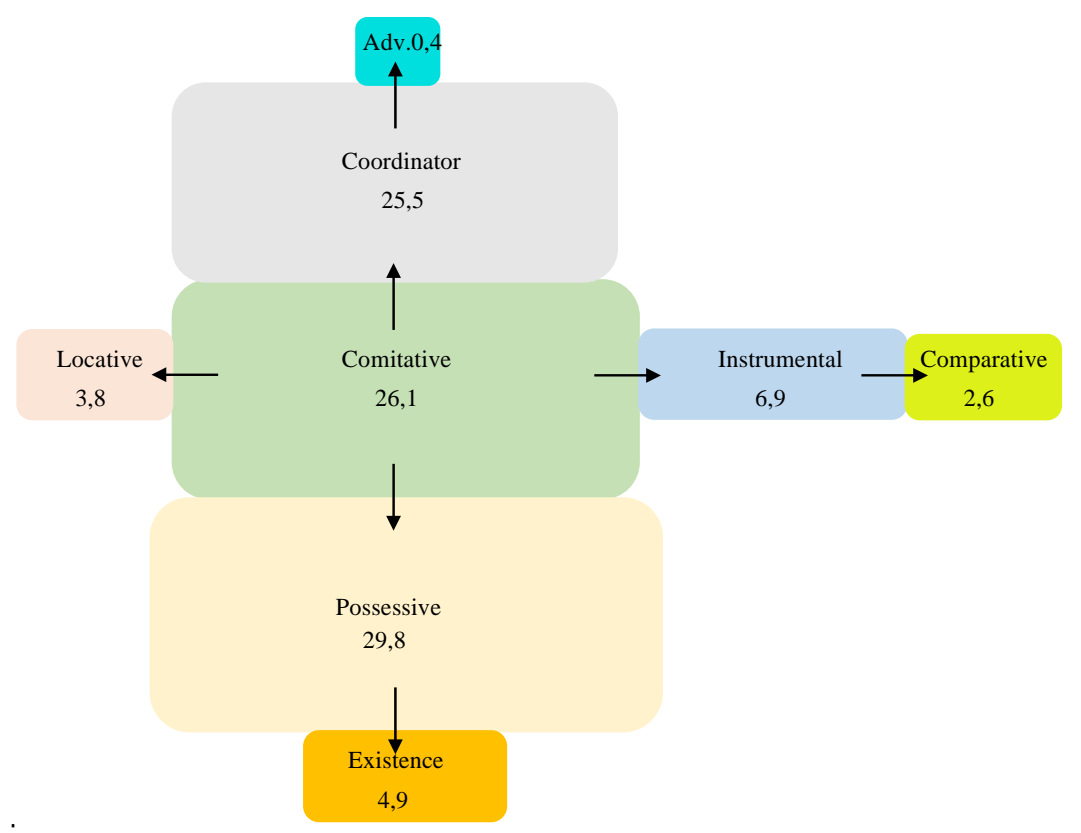

Figure 5: The qualitative-quantitative map of TI

Other "static" manners of visualization could be achieved by using differently shaped edges, particularly by altering their length or width (cf. Georgakopoulos \& Polis 2018:12-15; see section 2 above).

A more advantageous manner of incorporating the quantitative information into the qualitative model is to use the concept of a wave. This is because given its dynamics and gradience, the wave model is more representative of grammaticalization processes than a map - grammaticalization being the driving force of the form's map. However, due to certain limitations imposed by current editing programs, the wave model must be simplified into a cline in order to be presentable on paper. In the case of TI, the wave model can be posited if the quantitative-qualitative representation is reformulated into clines departing from the conceptual and diachronic center of the map - the comitative. Among several possibilities, four linear clines can be postulated: (a) from comitative to possessive and existence; (b) from comitative to adverbial; (c) from comitative to instrumental and comparative; and (d) from comitative to locative. These four clines can be represented by two diagrams - in each, two clines depart from a shared source. For instance, possessive/existence can be linked to coordinator/adverbial (Figure 6.a) and locative to instrumental/comparative (Figure 6.b). ${ }^{50}$ Both figures suggest that $\mathrm{TI}$ is a semi-advanced gram whose prototypicality center is located

\footnotetext{
${ }^{50}$ Alternative combinations are also possible.
} 
in the initial and intermediate stages of the grammaticalization paths: namely, the comitative and its immediate extensions, i.e. the possessive and the conjunctive coordinator (see Figure 6.a-b).

The above-mentioned semi-advancement of TI is consistent with other properties of that lexeme, in particular: (a) its incompatibility with the function of a clausal coordinator; (b) its limited ability to coordinate verbs (which is only possible with infinitives, themselves being verbal nouns, and in restricted contexts only); and (c) the impossibility of its use with a temporal and agentive sense, or in the function of a complementizer, concessive clausal conjunction, or discourse particle, which are all located in the peripheral zones of the map, and thus, at the end of the grammaticalization path underlying it.

(a) [existential < comitative $>$ adverbial] cline

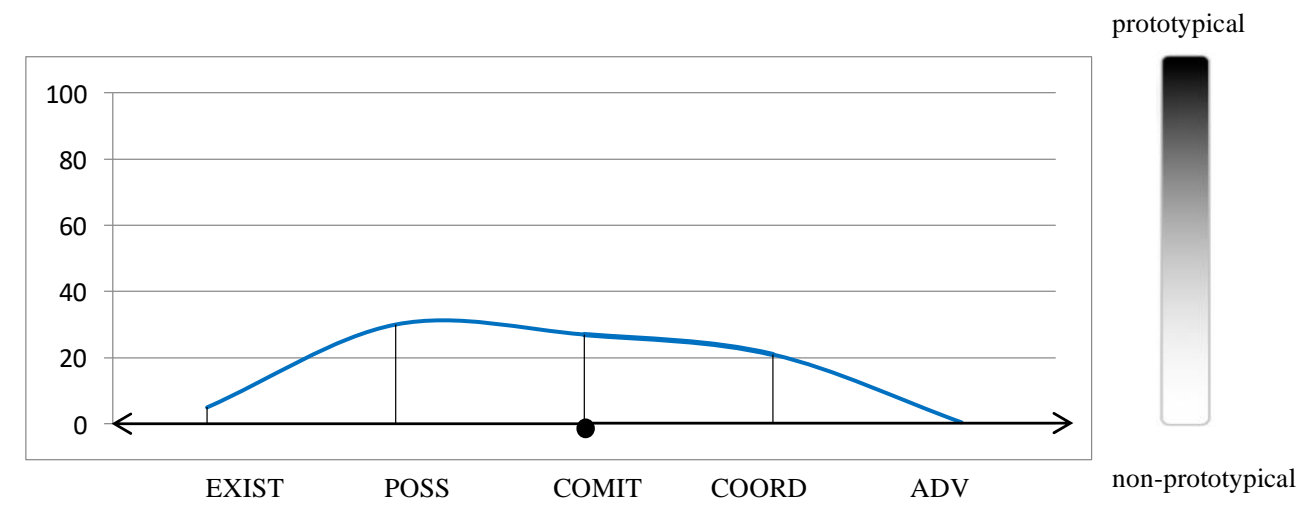

(b) [locative < comitative > comparison] cline

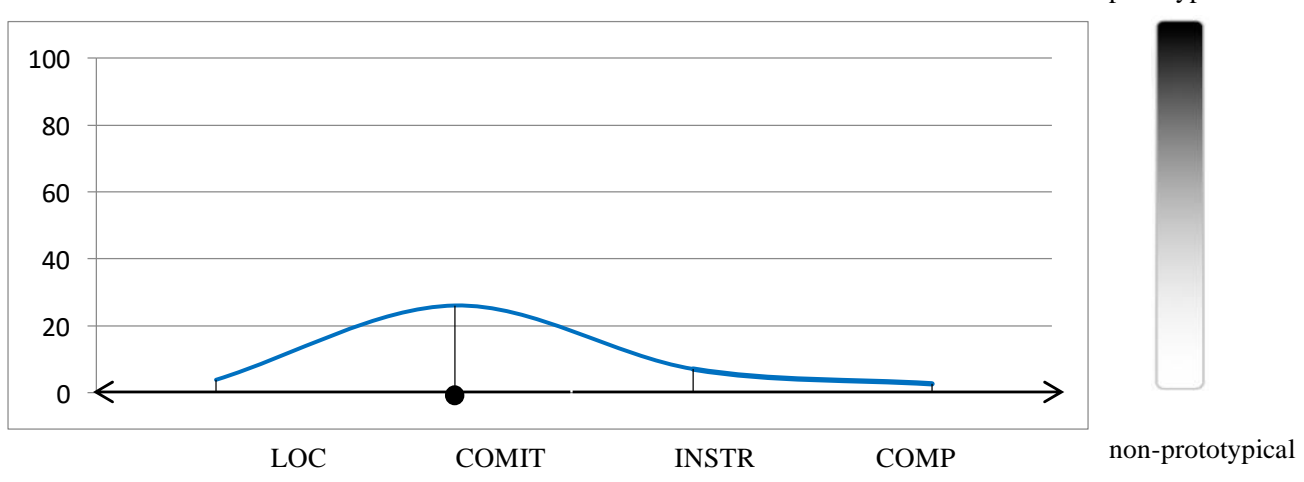

Figure 6: A wave model of $\mathrm{TI}^{51}$

\footnotetext{
${ }^{51}$ In these figures, the diachronic center of the wave (marked by the black dot) is the comitative. Therefore, the wave is represented as propagating in two directions (note the two arrows on the $x$ axis that represent the qualitative potential, i.e. senses or functions). This bi-diagrammatic and bi-directional representation could of course be combined into a single diagram with four directions leading towards four different attractors. The limitations of the available graphics prevent me from offering such a representation.
} 


\section{Conclusion}

The present article analyzed the polysemy and polyfunctionality of TI in Kituba from the perspective of cognitive linguistics, making use of the framework of dynamic semantic maps and waves. The qualitative and quantitative evidence demonstrates that TI is a semi-advanced gram whose prototypicality center is located in the initial (comitative) and intermediate stages (possessive and certain types of coordinate-hood) available along the grammaticalization network of conjunctive coordinators.

Additionally, the results of the study enabled me to introduce certain modifications to the typological grammaticalization-based map of conjunctive coordinators formulated by Haspelmath (2004) and subsequently expanded by Andrason (2017, forthcoming). New components of the map or grammaticalization stages were posited and alternative linking directions were proposed. Furthermore, I designed a novel manner of introducing quantitative data (related to prototypicality) to the traditional qualitative map of coordinate-hood. The resulting model was argued to exhibit properties characteristic of complexity: fuzziness, gradience, multi-causal relationships, and organizational intricacy.

Although the goal of this research and its objectives have been achieved, the paper has not explored the entire issue of the polysemy/polyfunctionality of conjunctive coordinators, neither in Kituba nor crosslinguistically. In forthcoming research, I will test the typological map formulated in this article on a large sample of languages from a wide phylum of linguistic families. Additionally, the search for a satisfactory quantitative representation - either in the form of a wave or in other forms - will continue. I believe that both research activities will enable me to refine the dynamic model of conjunctive coordinators and to understand their grammaticalization more accurately.

\section{Abbreviations:}

$\begin{array}{llll}\text { ADV } & \text { Adverb(ial) } & \text { IMP } & \text { Imperative } \\ \text { C } & \text { Category } & \text { INF } & \text { Infinitive } \\ \text { COMIT } & \text { Comitative } & \text { INSTR } & \text { Instrumental } \\ \text { COMP } & \text { Comparative } & \text { LOC } & \text { Locative } \\ \text { COMPL } & \text { Complementizer } & \text { N-COORD } & \text { Nominal Coordinator } \\ \text { COORD } & \text { Coordinator } & \text { PERF } & \text { Perfect } \\ \text { DISC PART } & \text { Discourse Particle } & \text { PRES } & \text { Present } \\ \text { EXIST } & \text { Existence } & \text { PP-COORD } & \text { Prepositional-Phrase Coordinator } \\ \text { EXPL } & \text { Expletive } & \text { POSS } & \text { Possessive } \\ \text { FUT } & \text { Future } & \text { V-COORD } & \text { Verbal Coordinator } \\ \text { HAB } & \text { Habitual } & & \end{array}$




\section{References}

Andrason, Alexander. 2016a. From vectors to waves and streams: An alternative approach to semantic maps. Stellenbosch Papers in Linguistics 45. 1-29.

Andrason, Alexander. 2016b, A complex system of complex predicates: Tense, taxis, aspect and mood in Basse Mandinka from a grammaticalization and cognitive perspective. Stellenbosch: Stellenbosch University dissertation.

Andrason, Alexander. 2016c. The coordinators i and $\mathrm{z}$ in Polish: A cognitive-typological approach. Part 1. Lingua Posnaniensis 58(1). 7-24.

Andrason, Alexander. 2017. The coordinators i and z in Polish: A cognitive-typological approach. Part 2. Lingua Posnaniensis 59(2). 7-22.

Andrason, Alexander. (forthcoming). The conjunctive coordinator NA in Xhosa - its categorial status and map of polyfunctionality. Italian Journal of Linguistics 30(2).

Andrason, Alexander. (under review). A contribution to the semantic map of adversative-contrastive markers - Evidence from Polish.

Andrason, Alexander \& Christian Locatell. 2016. The perfect wave. Biblical and Ancient Greek Linguistics 5: 7-121.

Auyang, Sunny. 1998. Foundations of complex-system theories. Cambridge: Cambridge University Press.

Ayibite, Pela Asey. 1983. Du kikongo au kituba: Un cas de pidginisation d'une variété véhiculaire bantu. Africanistique 12. 12-44.

Biblia: Mbalula ya ntsi-ntoto ya mpa. 2015. Watch Tower Bible and Tract Society of Pennsylvania. (http://wol.jw.org/kg/wol/lv/r271/lp-mk/0/0)

Bokamba, Eyamba. 1985. Verbal agreement as a noncyclic rule in Bantu. In Didier Goyvaerts (ed.), African Linguistics, 9-54. Amsterdam: John Benjamins.

Bostoen, Koen, Sebastian Dom \& Guillaume Segerer. 2015. The antipassive in Bantu. Linguistics 53(4). 731-772.

Bosch, Sonja. 1985. Subject and object agreement in Zulu. Pretoria: University of Pretoria MA dissertation.

Botne, Robert. 2003. Lega (Beya dialect). In Derek Nurse \& Gérard Philippson (eds.), The Bantu languages, 422-449. London: Routledge.

Bybee, Joan, Revere Perkins \& William Pagliuca. 1994. The evolution of grammar. Chicago: The University of Chicago Press.

Creissels, Denis. 2016. Additive coordination, comitative adjunction, and associative plural in Tswana. Linguistique et langues africaines 2. 11-42.

Creissels, Denis, Gerrit J. Dimmendaal, Zygmunt Frajzyngier \& Christa Koönig. 2008. Africa as a morphosyntactic area. In Bernd Heine \& Derek Nurse (eds.), A linguistic geography of Africa, 86-150. Cambridge: Cambridge University Press.

Creissels, Denis \& Sylvie Voisin-Nouguier. 2008. Valency-changing operations in Wolof and the notion of co-participation. In Ekkehard König \& Volker Gast (eds.), Reciprocals and reflexives: Theoretical and typological explorations, 293-309. Berlin \& New York: Mouton de Gruyter.

Croft, William \& D. Alan Cruse. 2004. Cognitive linguistics. Cambridge: Cambridge University Press. Cuyckens, Hubert \& Britta Zawada (eds.). 1999. Polysemy in cognitive linguistics. Amsterdam: John Benjamins. 
Cysouw, Michael. 2007. Building semantic maps: The case of person marking. In Berhard Wälchli \& Matti Miestamo (eds.), New challenges in typology, 225-248. Berlin \& New York: Mouton de Gruyter.

Dąbrowska, Ewa \& Dagmar Divjak (eds.). 2015. Handbook of cognitive linguistics. Berlin: De Gruyter Mouton.

De Vos, Mark \& Hazel Mitchley. 2012. Subject marking and preverbal coordination in Sesotho: a perspective from Optimality Theory. Southern African Linguistics and Applied Language Studies 30(2). 155-170.

Donzo, Jean-Pierre. 2015. Bantu languages of the Congo-Ubangi from DRCongo: documentation, reconstruction, classification and contact with Ubangian languages. Afrika Focus 28 (1). 109120.

Du Plessis, Jacobus A. 1978. IsiXhosa 4. Goodwood: Oudiovista.

Evans, Vyvyan. 2006. Lexical concepts, cognitive models and meaning-construction. Cognitive Linguistics 17(4). 491-534.

Evans, Vyvyan. 2015. A unified account of polysemy within LCCM theory. Lingua 157. 100-123.

Evans, Vyvyan \& Melanie Green. 2006. Cognitive linguistics: an introduction. Edinburgh: Edinburgh University Press.

Falkum, Ingrid \& Augustin Vicente. 2015. Polysemy: current perspectives and approaches. Lingua 157. 1-16.

Fehderau, Harold. 1966. The origin and development of Kituba. Ithaca: Cornell University dissertation.

Fleisch, Axel. 2005. Agent phrases in Bantu passives. In Erhard Voeltz (ed.), Studies in African linguistic typology, 93-111. Amsterdam: John Benjamins.

Geeraerts, Dirk. 2010. Theories of lexical semantics. Oxford: Oxford University Press.

Georgakopoulos, Thanasis \& Stéphane Polis 2018. The semantic map model: State of the art and future avenues for linguistic research. Language and Linguistic Compass 12(2). 1-33. e12270.

Gilquin, Gaëtanelle. 2006. The place of prototypicality in corpus linguistics. In Stefan Gries \& Anatol Stefanowitsch (eds.), Corpora in cognitive linguistics, 159-191. Berlin: Mouton de Gruyter.

Givón, Talmy. 1970. The resolution of gender conflicts in Bantu conjunctions: when syntax and semantics clash. In Papers from the $6^{\text {th }}$ Regional Meeting, Chicago Linguistic Society, April 16-18, 250-261. Chicago: CLS.

Glynn, Dylan. 2010. Corpus-driven cognitive semantics introduction to the field. In Dylan Glynn \& Kerstin Fischer (eds.), Quantitative methods in cognitive semantics: Corpus-driven approaches, 1-41. Berlin: De Gruyter Mouton.

Glynn, Dylan \& Kerstin Fischer (eds.). 2010. Quantitative methods in cognitive semantics: Corpus-driven approaches. Berlin: De Gruyter Mouton.

Gries, Stefan. 2006. Corpus-based methods and cognitive semantics. In Stefan Gries \& Anatol Stefanowitsch (eds.), Corpora in Cognitive Linguistics, 57-99. Berlin: Mouton de Gruyter.

Gries, Stefan \& Dagmar Divjak. 2010. Quantitative approaches in usage-based cognitive semantics: myths, erroneous assumptions, and a proposal. In Dylan Glynn \& Kerstin Fischer (eds.), Quantitative methods in cognitive semantics: Corpus-driven approaches, 333-353. Berlin: De Gruyter Mouton.

Gries, Stefan \& Anatol Stefanowitsch (eds.). 2006. Corpora in cognitive linguistics. Berlin: Mouton de Gruyter. 
Guthrie, Malcolm. 1970. Comparative Bantu: an introduction to the comparative linguistics and prehistory of the Bantu languages. Vols. 1-4. Farnborough: Gregg Press.

Haspelmath, Martin. 2003. The geometry of grammatical meaning semantic maps and crosslinguistic comparison. In Michael Tomasello (ed.), The new psychology of language, 211-242. Mahwah: Lawrence Erlbaum Associates.

Haspelmath, Martin. 2004. Coordinating constructions: An overview. In Martin Haspelmath (ed.), Coordinating Constructions, 1-40. Amsterdam: John Benjamins.

Haspelmath, Martin. 2007. Coordination. In Timothy Shopen (ed.), Language typology and syntactic description. Vol.. II: Complex constructions, 1-51. Cambridge: Cambridge University Press.

Heine, Bernd. 1997a. Cognitive foundations of grammar. Oxford: Oxford University Press.

Heine, Bernd. 1997b. Grammaticalization theory and its relevance to African linguistics. In Robert Herbert (ed.), African linguistics at the crossroads: Papers from Kwaluseni ( $1^{\text {st }}$ World Congress of African Linguistics, Swaziland, 18-22 July), 1-15. Köln: Rüdiger Köppe.

Heine, Bernd \& Tania Kuteva. 2002. World lexicon of grammaticalization. Cambridge: Cambrige University Press.

Hochegger, Hermann. 1983 Dictionnaire français - kikongo ya leta. Bandundu: CEEBA.

Hooker, Cliff (ed.). 2011. Philosophy of complex systems. Amsterdam: Elsevier.

Janda, Laura. 2002. Cognitive hot spots in the Russian case system. In Michael Shapiro (ed.), Peircean Semiotics: The State of the Art, 165-188. New York: Berghahn Books.

Janda, Laura. 2015. Cognitive linguistics in the Year 2015. Cognitive Semantics 1. 131-154.

Johannessen, Janne. 1998. Coordination. Oxford: Oxford University Press.

Kilian-Hatz, Christa. 1992. Der Komitativ im Baka: Eine Fallstudie zur Grammatikalisierung. Cologne: Universität zu Köln MA dissertation.

Kilian-Hatz, Christa \& Thomas Stolz. 1992. Comitative, concomitance, and beyond: On the interdependency of grammaticalization and conceptualization. Cologne: Institut für Afrikanistik, Universität zu Köln.

Kortmann, Bernd. 1997. Adverbial subordination: A typology and history of adverbial subordinators based on European languages. Berlin: Mouton de Gruyter.

Lamb, Sydney M. 1999. Pathways of the brain. The neurocognitive basis of language. Amsterdam: John Benjamins.

Malchukov, Andrej. 2004. Towards a Semantic Typology of Adversative and Contrast Marking. Journal of Semantics 21. 177-198.

Marten, Lutz. 2000. Agreement with conjoined noun phrases in Swahili. Afrikanistische Arbeitspapiere 64. 75-96.

Marten, Lutz. 2003. Dynamic and pragmatic partial agreement in Luguru. In Patrick Sauzet \& Anee Zribi-Hertz (eds), Typologie des langues d'Afrique et universaux de la grammaire. Vol. 1, 113139. Paris: L'Harmattan.

Marten, Lutz. 2005. The dynamics of agreement and conjunction. Lingua 115. 527-547.

Marten, Lutz. 2011. Information structure and agreement: Subjects and subject markers in Swahili and Herero. Lingua 121. 787-804.

Marten, Lutz. 2013. Structure and interpretation in Swahili existential constructions. Italian Journal of Linguistics 25(1). 45-73.

Massip-Bonet, Àngeles \& Albert Bastardas-Boada (eds.). 2013. Complexity perspectives on language, communication and society. Heidelberg: Springer 
Mauri, Caterina. 2007. Conjunctive, disjunctive and adversative constructions in Europe: Some areal considerations. In Paolo Ramat \& Elisa Roma (eds.), Europe and the Mediterranean Linguistic Areas, 183-214. Amsterdam: Benjamins.

Mauri, Caterina. 2008. Coordination relations in the languages of Europe and beyond. Berlin: Mouton de Gruyter.

Mauri, Caterina. 2010. Semantic maps or coding maps? Towards a unified account of the coding degree, coding complexity, and coding distance of coordination relations. Linguistic Discovery 8(1). 210-232.

Meeussen, Achille. 1969 [1981]. Bantu lexical reconstructions. Tervuren: Musée Royal de l'Afrique Centrale.

Miestamo, Matti, Kaius Sinnemäki \& Fred Karlsson (eds.). 2008. Language complexity: Typology, contact, change. Amsterdam: John Benjamins.

Mithun, Marianne. 1988. Grammaticalization of coordination. In John Haiman \& Sandra Thompson (eds.), Clause combining in grammar and discourse, 331-361. Amsterdam: Benjamins.

Mkude, Daniel J. 1996. Prototypicality and the syntax of possession in Swahili. Journal of Asian and African Studies 51. 1-10.

Mous, Maarten. 2004. The grammar of conjunctive and disjunctive coordination in Iraqw. In Martin Haspelmath (ed.), Coordinating constructions, 109-122. Amsterdam: John Benjamins.

Mous, Maarten \& Mreta Abel. 2004. The comitative/conjunctive preposition na in Chathu (Pare), a Bantu language of Tanzania. South African Journal of African Languages 24(4). 219-229.

Mufwene, Salikoko. 1988. Formal evidence of pidginization/creolization in Kituba. Journal of African Languages and Linguistics 10. 33-51.

Mufwene, Salikoko. 1989. La créolisation en bantou : les cas du kituba, du lingala, et du swahili du Shaba. Études Créoles 12. 74-106.

Mufwene, Salikoko. 1997. Kitúba. In Sarah G. Thomason (ed.), Contact languages: A wider perspective, 173-208. Amsterdam: John Benjamins.

Mufwene Salikoko. 2001. The ecology of language evolution. Cambridge: Cambridge University Press.

Mufwene, Salikoko. 2003. Contact languages in the Bantu area. In Nurse Derek \& Gérard Philippson (eds.), The Bantu languages, 195-208. London: Curzon Press.

Mufwene, Salikoko. 2005. Kituba. In Philipp Strazny (ed.), Encyclopedia of linguistics, 577-579. New York: Fitzroy Dearborn.

Mufwene, Salikoko. 2009. Kituba, Kileta, or Kikongo? What's in a name?. In Carole de Féral (ed.), Le nom des langues III. Le nom des langues en Afrique sub-saharienne: pratiques dénominations, catégorisations, 211-222. Louvain-la-Neuve: Peeters.

Mufwene, Salikoko. 2013. The emergence of complexity in language: An evolutionary perspective. In Àngeles Massip-Bonet \& Albert Bastardas-Boada (eds.), Complexity perspectives on language, communication and society, 197-218. Heidelberg: Springer.

Mufwene, Salikoko, Christophe Coupé \& François Pellegrino (eds.). 2017. Complexity in Language Developmental and Evolutionary Perspectives. Cambridge: Cambridge University Press.

Mufwene, Salikoko, Christophe Coupé \& François Pellegrino. 2017. Complexity in Language: A Multifaceted Phenomenon. In Salikoko Mufwene, Christophe Coupé \& François Pellegrino (eds.), Complexity in Language Developmental and Evolutionary Perspectives, 1-29. Cambridge: Cambridge University Press. 
Narrog, Heiko. 2010. A diachronic dimension in maps of case functions. Linguistic Discovery 8(1). 233-254.

Narrog, Heiko \& \& Shinya Ito. 2007. Re-constructing semantic maps: The comitative-instrumental area. STUF - Language Typology and Universals, 60(4). 273-292.

Narrog, Heiko \& Johan van der Auwera. 2011. Grammaticalization and semantic maps. In Heiko Narrog \& Bernd Heine (eds.), The Oxford handbook of grammaticalization, 318-327. Oxford: Oxford University Press.

Paperno, Denis. 2012. Semantics and syntax of non-standard coordination. Los Angeles: University of California PhD Dissertation.

Payne, John. 1985. Complex phrases and complex sentences. In Timothy Shopen (ed.), Language typology and syntactic description. Vol. 2. Complex constructions, 3-41. Cambridge: Cambridge University Press.

Riemer, Nick. 2010. Introducing semantics. Cambridge: Cambridge University Press.

Riemer, Nick. 2016. The Routledge handbook of semantics. Abingdon: Routledge

Rwanika, Mwisha. 1986. Kikongo. Livre du formateur. Bukavu: Peace Corps.

Samarin, William J. 1982. Colonization and pidginization on the Ubangi River. Journal of African Languages and Linguistics 4. 1-42.

Samarin, William J. 1990. The origins of Kituba and Lingala. Journal of African Languages and Linguistics 23. 47-77.

Sampson, Geoffrey, David Gil \& Peter Trudgill (eds.). 2009. Language complexity as an evolving variable. Oxford: Oxford University Press.

Schladt, Mathias. 1998. Reciprocals in Bantu languages. Afrikanistische Arbeitspapiere 53. 5-25.

Schneider-Zioga, Patricia. 2015. Additive focus in Kinande. In Ruth Kramer, Elizabeth C. Zsiga \& One Tlale Boyer (eds.), Selected Proceedings of the $44^{\text {th }}$ Annual Conference on African Linguistics, 254-263. Somerville, MA: Cascadilla Proceedings Project

Sineke, Thembela G. 1997. Agreement and concord with conjoined Noun Phrases in Xhosa. Stellenbosch: Stellenbosch University MA Dissertation.

Sivundla, Koleka P. 1987. Some observations on Xhosa coordination. Stellenbosch: Stellenbosch University MA Dissertation.

Swartenbroeckx, Pierre. 1973. Dictionnaire kikongo et kituba - français. Bandundu: CEEBA.

Van der Auwera, Johan. 2013. Semantic maps, for synchronic and diachronic typology. In Anna Giacalone Ramat, Caterina Mauri \& Piera Molinelli (eds.), Synchrony and diachrony. A dynamic interface, 153-176. Amsterdam: John Benjamis.

Voeltz, Erhard. 1971. Surface constraints and agreement resolution: Some evidence from Xhosa. Studies in African Linguistics 2(1). 37-60.

Vydrin, Valentin. 2010. Co-ordinative pronouns in Southern and South-Western Mande: A second compound pronouns area in Africa? In Konstantin Pozdniakov, Valentin Vydrin \& Aleksandr Zheltov (eds.), Personal pronouns in Niger-Congo languages: International workshop (St. Petersburg, Sept. 13-15, 2010). Abstracts and papers: Working materials, 164-172. St. Petersburg: St. Petersburg University Press.

Zwarts, Joost. 2010. Semantic map geometry: Two approaches. Linguistic Discovery 8(1). 377-395. 
Alexander Andrason <andrason@sun.ac.za>

Stellenbosch University

Ancient Studies

South Africa. 